\title{
The "other" time: a review of the subjective experience of time in organizations
}

Article

Accepted Version

Shipp, A. J. and Jansen, K. J. (2021) The "other" time: a review of the subjective experience of time in organizations. Academy of Management Annals, 15 (1). pp. 299-334. ISSN 1941-6067 doi: https://doi.org/10.5465/annals.2018.0142 Available at https://centaur.reading.ac.uk/95567/

It is advisable to refer to the publisher's version if you intend to cite from the work. See Guidance on citing.

To link to this article DOI: http://dx.doi.org/10.5465/annals.2018.0142

Publisher: Academy of Management

All outputs in CentAUR are protected by Intellectual Property Rights law, including copyright law. Copyright and IPR is retained by the creators or other copyright holders. Terms and conditions for use of this material are defined in the End User Agreement.

$\underline{\text { www.reading.ac.uk/centaur }}$ 
Central Archive at the University of Reading

Reading's research outputs online 
THE “OTHER" TIME: A REVIEW OF THE SUBJECTIVE EXPERIENCE OF TIME IN ORGANIZATIONS

\author{
Abbie J. Shipp \\ Texas Christian University \\ a.shipp@tcu.edu \\ Karen J. Jansen \\ Henley Business School \\ karen.jansen@henley.ac.uk
}

IN PRESS AT ACADEMY OF MANAGEMENT ANNALS

PLEASE DO NOT CITE OR DISTRIBUTE WITHOUT PERMISSION

Author note: We would like to thank Daan van Knippenberg and Marya Besharov for their editorial guidance during the development of this manuscript. We would also like to thank Blake Ashforth for incredibly helpful suggestions on an earlier version of the manuscript. 


\begin{abstract}
Time - whether objective ("clock") time or the subjective experience of time-is essential for understanding how individuals, teams, and organizations evolve, grow, learn, and change. Yet most management research and literature reviews typically emphasize objective time to the exclusion of subjective time. Our review focuses on this lesser studied "other" time, beginning with a review of how seminal time articles have historically conceptualized subjective time. From this initial review, we offer an integrative and multilevel definition of subjective time as the experience of the past, present, and future, which occurs as individuals and collectives mentally travel through, perceive, and interpret time. Then, using this new definition to frame the remainder of the review, we examine the literature employing subjective time concepts to address three key questions: what is subjective time, how does it operate, and why does it matter? Our analysis provides new ways for understanding subjective time and the important role it plays in organizational phenomena. We conclude by challenging management scholars to consider three priorities for future research: the fundamental relationship between subjective time and meaning, the unclear nature of event time, and the ways in which objective time is dependent upon subjective time.
\end{abstract}




\section{THE "OTHER" TIME: A REVIEW OF THE SUBJECTIVE EXPERIENCE OF TIME IN ORGANIZATIONS}

"It is really true what philosophy tells us, that life must be understood backwards. But with this, one forgets the second proposition, that it must be lived forwards. A proposition which, the more it is subjected to careful thought, the more it ends up concluding precisely that life at any given moment cannot really ever be fully understood; exactly because there is no single moment where time stops..."

-Søren Kierkegaard, Journalen JJ:167, 1843/1997

A few decades ago, a number of influential scholars identified the emerging importance of time for understanding the field of management (Ancona, Okhuysen, \& Perlow, 2001; Bluedorn, 2002; Bluedorn \& Denhardt, 1988; George \& Jones, 2000; McGrath \& Rotchford, 1983; Mitchell \& James, 2001). They concluded that time is essential for understanding the process by which individuals, teams, and organizations evolve, grow, learn, and change. These seminal frameworks typically position time as either objective (i.e., the actual passage of time based on the clock and calendar) or subjective (i.e., experiencing the past, present, and future within the current moment).

In reality, however, time is composed of both elements simultaneously, making objective and subjective time inherently intertwined (Jaques, 1982). As organizational actors, we are well aware that, in any given moment, one can mentally time travel through time (e.g., retrospecting about the past or anticipating the future) while also experiencing the ticking of the clock. For example, an individual may worry about a meeting tomorrow while hurrying to today's meeting, or an organization may rely on past stories to reinforce its current culture. Simply stated, whereas objective time emphasizes "snapshots" of experience across the actual passage of time (i.e., time as "a constant rather than a variable"; Das, 1993, p. 268), subjective time draws attention to perceptions of the past, present, and future, emphasizing a narrative that connects the snapshots into a meaningful "movie" (Weisbord, 1988). The important insight here is that people naturally and constantly experience both elements of time as noted by the Kierkegaard quote above. 
Yet as scholars, we have tended to separate the two types of time as if they are distinct or even contradictory (Orlikowski \& Yates, 2002). Rather than adopting a paradox stance in which both are possible, most scholars have presumed that accounting for one automatically precludes the other (Reinecke \& Ansari, 2015; Slawinski \& Bansal, 2017). To this point, some have noted that organizational research tends to emphasize objective time over subjective time (cf. Bluedorn \& Denhardt, 1988; Cronin, Weingart, \& Todorova, 2011; George \& Jones, 2000; Kunisch, Bartunek, Mueller \& Huy, 2017; McGrath \& Rotchford, 1983; Mosakowski \& Earley, 2000). This is an interesting oversight because subjective time is the key aspect of time that lends meaning to one's life and work (e.g., Baumeister, Vohs, \& Oettingen, 2016; Dawson, 2014; Lewin, 1943; Murray, 1938). For example, subjective time helps people to interpret organizational change as positioned against the past and future (e.g., Lord, Dinh, \& Hoffman, 2015; Suddaby \& Foster, 2017), creating meaning-imbued narratives of the past, present, and future to signify what has changed or will change (e.g., Wolfram-Cox, 1997; Ybema, 2010).

These examples and others demonstrate that subjective time concepts can improve our understanding of organizational phenomena above and beyond objective time (Huy, 2001). For example, Slawinski and Bansal (2012) discussed how viewing an organization's time perspective as cyclical (a subjective time concept) better explains strategic climate change responses beyond a linear perspective (objective time). Similarly, Fried and Slowik (2004) proposed that individuals' perception of the past, present, and future shapes their ability to set and perform towards future goals in ways that objective time cannot address. In countless examples, it is clear that subjective time can offer important insights within the field of management.

Despite these insights, the field has yet to establish a cumulative body of research on the topic of subjective time. A few reviews touching aspects of subjective time are beginning 
to emerge, focusing on the meaning of time use (Feldman, Reid, \& Mazmanian, 2020) or trait versus state differences (Tang, Richter, \& Nadkarni, 2020). However, the field lacks a systematic and holistic synthesis of the critical aspects of subjective time across levels and research domains. A spotlight on this "other" aspect of time is long overdue.

Our goal in this review is to provide insight into three major aspects of subjective time: what it is, how it operates, and what it impacts. This review is somewhat different from others in which a well-established construct may be situated within the boundaries of a single research domain. In contrast, we seek to raise awareness of where subjective time concepts are present in the literature (explicitly or implicitly), breaking down boundaries across levels of analysis, research domains, and temporal "thought worlds" (Dougherty, 1992). As such, this review is relevant for scholars studying any time-relevant topic, including organizational phenomena that change or evolve over the passage of objective time, or specific subjective time concepts from research domains including cognition, strategy, identity, or organizational change.

In what follows, we first provide a brief history of how conceptualizations of time have evolved in the literature. We draw upon a set of seminal time articles to establish an integrative definition of subjective time, and we then use the various components of our definition to conduct a review of articles in the management literature as a whole. This review makes three broad contributions. First, we establish a clear delineation of the scope of subjective time (i.e., what it is), including an integrative definition and an examination of three cognitive actions comprising subjective time. ${ }^{1}$ Second, we synthesize the array of available mechanisms to explain the processes by which subjective time actions transmit their effects (i.e., how subjective time operates). Third, we account for the impact offered when utilizing subjective time actions and mechanisms (i.e., why subjective time matters for

\footnotetext{
${ }^{1}$ A glossary of subjective time terms used throughout the paper is provided in the Appendix.
} 
management research). Beyond specific calls to action we raise throughout the review, we conclude with three important but challenging directions for future research.

\section{A HISTORY OF THE CONCEPTUALIZATION(S) OF SUBJECTIVE TIME AND A PROPOSED DEFINITION}

But what now is manifest and clear is, that neither are there future nor past things. Nor is it right to say, "There are three times, past, present and future." But it might be right to say, "There are three times; a present of things past, a present of things present, and a present of things future." For these three times do somehow exist in the soul.

-Saint Augustine (Book XI, Chapter 20, Heading 26)

To begin, it is helpful to briefly identify the earliest ideas about subjective time and how this concept moved into the field of management. ${ }^{2}$ The general concept of subjective time first appeared in the writings of Saint Augustine's Book XI of the Confessions (AD 397401). In contrast to Plato and Aristotle who portrayed time as chronological and continuous, Saint Augustine grappled with the paradoxical nature of time as both an inherent characteristic of the universe (i.e., objective time) and an inherent characteristic of human consciousness (i.e., subjective time). As noted by the quote above, his acknowledgement that memory, perception, and anticipation are essential aspects of human experience provides the most notable origin of the subjective time concept.

Subsequent scholars have continued to explore this dual nature of time, typically pitting objective and subjective time against each other. Particularly at the start of the $20^{\text {th }}$ century, the social sciences distinguished between chronos and kairos (i.e., the chronological measure of time versus the qualitative interpretation of the "right time"), absolute versus relative time, astronomical versus social time, and linear versus cyclical time (Bluedorn, 2002). In contrast to prior beliefs that time is homogeneous, measurable, and universal, early scholars in psychology and sociology were additionally interested in subjective time questions such as how individuals mentally travel to the past and future to provide a context

\footnotetext{
${ }^{2}$ For additional historical details, we point readers to Bluedorn (2002).
} 
for current experiences (e.g., Lewin, 1943); how they perceive duration within the "present" moment (e.g., Russell, 1915); and how they collectively structure their time through social events to facilitate coordination and shared meaning (e.g., Durkheim, 1915; Sorokin \& Merton, 1937).

The field of management began adopting these ideas in the mid- to late $20^{\text {th }}$ century when exploring how individuals and collectives experience both objective and subjective time at work. For example, McGrath and Rotchford (1983) addressed the importance of both types of time for organizations' scheduling, synchronization, and allocation of time across individuals. Similarly, Schriber and Gutek (1987) explored the temporal dimensions of organizational culture such as socially constructed time boundaries, organizational time awareness, and organizational future orientation. The end of the $20^{\text {th }}$ century culminated in a spate of articles generally acknowledging that subjective time is distinct from objective time (e.g., Ancona et al., 2001; Bluedorn, 2002; Bluedorn \& Denhardt, 1988; George \& Jones 2000; McGrath \& Rotchford, 1983; Mitchell \& James, 2001). ${ }^{3}$ For example, Ancona et al. (2001) discuss how scholars have critically contrasted "objective time with subjective time, homogeneous with heterogeneous, regular with irregular, precise with imprecise, reversible with irreversible, [and] objective with experiential...”. Lee and Liebenau (1999) concur by stating that "...time is socially constructed...the social time concept [is] the antithesis of the concept of clock time" (p. 1040). These contrasts pit the absolute nature of objective time (i.e., homogeneous units such as minutes, hours, or days; McGrath \& Rotchford, 1983) against the relativistic aspects of subjective time (i.e., time that is heterogeneously construed by individuals and collectives). Overall, the management literature's interest in the topic of time has continued to grow, particularly with increasing attention to the importance of

\footnotetext{
${ }^{3}$ Given that we focus predominantly on subjective time, we point readers interested in objective time to a myriad of reviews and conceptual papers, including Cronin, Weingart, and Todorova (2011), Kunisch et al. (2017), Mitchell and James (2001), Mosakowski \& Earley (2000), Pitariu \& Ployhart (2010), Ployhart \& Vandenberg (2010), Roe (2008), Shipp \& Cole (2015), and Zaheer, Albert, \& Zaheer (1999).
} 
subjective time.

Interestingly, beyond the knowledge that subjective time is a distinct aspect of time, scholars to date have yet to reach a clear definition, which is a crucial element for guiding this review. Therefore, we examined 32 heavily cited management pieces to ascertain their conceptualization of subjective time. ${ }^{4}$ As the definitions reported in Table 1 reveal, most of the seminal articles offer their own unique conceptualization, with no single definition emerging to represent the subjective time concept.

\section{INSERT TABLE 1 HERE}

To better synthesize the various views, we searched for commonalities across the definitions from the seminal articles and derived the following multidimensional definition:

Subjective time is the experience of the past, present, and future, which occurs as individuals (intrasubjectively) and collectives (intersubjectively) mentally travel through, perceive, and interpret time.

Three major components of this definition stand out as important for understanding the subjective time perspective. First, subjective time reflects the experience of all three time frames: past, present, and future. As shown by the quote in Table 1, Lewin (1943) proposed that the psychological field of experience in the current moment (i.e., time $t$ ) is experienced within the context of the "psychological past" and the "psychological future." Lewis \& Weigert (1981) concurred, stating that "without a sentient, rational being there is no past, present, or future, nor even a before or after. These structures are imposed on the world by

\footnotetext{
${ }^{4}$ Our search for seminal articles yielded 20 conceptual articles, 9 books, and 3 qualitative papers, most of which were published between 1980 and 2010 (denoted by ** in the reference list). Because strong conceptualization derives from both what a concept is and what it is not, we paid special attention to articles that contrasted subjective time with objective time, and we traced conceptualizations backwards to identify the most influential publications upon which definitions of subjective time were based.
} 
our minds" (p. 435). What is most important about this aspect of our definition is that individuals engage with time holistically, such that "the continuously present field of pastpresent - future...coexist in the interaction of memory, perception, desire, and anticipation." (Jaques' 1982; p. 87).

Second, subjective time can be described as both a product of social construction and an element of individual perception: "intersubjective time" and "intrasubjective time" respectively (cf. Hernadi, 1992). As shown in Table 1, intersubjective time addresses how collectives co-create the experience of time through social construction (e.g., created through social norms that provide the meaning of time; Cunliffe, Luhman, \& Boje, 2004), and/or event time (e.g., shaped by events, rather than the clock, to include event-based cycles and rhythms; Bluedorn, 2002). In contrast, intrasubjective time accounts for how individuals experience time through psychological time travel (e.g., individualized views of the past and future; George \& Jones, 2000; Lewin, 1943), and/or the perceived duration of time (e.g., perception of the passing of the current moment; Block, 1990; Doob, 1971).

Finally, our definition highlights three cognitive actions comprising subjective time: mentally traveling forward and backward in time, perceiving time itself, and interpreting the meaning of time. Unlike objective time, which is external to the individual (i.e., people are the object), subjective time brings in individual and collective action in the form of cognition about time (i.e., people are the subject). Mental time travel occurs when people repeatedly move backward and forward in time to revisit past memories or future plans. For example, Shipp and Cole (2015) described how subjective time is "cognitively cyclical—-thoughts may move between past, present, and future in any direction...” (p. 239). Such time travel can occur individually or in collectives when "organizational participants intentionally attempt, in the present, to connect the past to the future," such as in decision making contexts (Butler, 1995, p. 926). 
Beyond simply traveling to the past and future, subjective time also addresses a sense of perception, whether perceiving the passing of time itself (e.g., Doob, 1971) or perceiving the temporal structure of past, present, or future experiences (e.g., linearity, novelty, regularity, or pace; Butler, 1995). For example, Bergadaà (1990) referred to "personal time" as "the individual's perception of past, present, and future," (p. 291), such as the perceived distance to a future goal. Similarly, Block (1990) wrote that "psychological time" allows individuals to "perceive successiveness and temporal order" (p. 1). In both cases, people may differentially perceive time itself whether temporal distance to the past or future or idiosyncratic perceptions of how quickly the present moment passes.

Finally, subjective time emphasizes the important role of interpretation, which goes beyond time travel and the perception of time itself to highlight the meaning and significance of time across past, present and future. For example, Avital (2000) states that "temporal elements do not merely change one's perception of a situation, but also provide a space for a richer and more meaningful interpretation...” (pp. 669-670). Cunliffe et al. (2004) adds an element of collective interpretation by acknowledging that people "interpret the past through the present and see those facts through acts of interpretation and social construction" (p. 272).

In sum, our review of the seminal articles led us to conclude that subjective time is not a singular concept; it is multidimensional. The concept also spans levels, from the psychological aspects of time in individuals' minds to the sociological aspects of time within collectives. And finally, it is comprised of three primary actions: mentally time traveling, perceiving time itself, and interpreting the meaning of time. Perhaps most important, unlike objective time in which people are acted upon by an external measure of time, subjective time highlights the critical and simultaneous experience of past, present and future as individuals and collectives act within and upon their internal, cognitive sense of time. 


\section{A REVIEW OF SUBJECTIVE TIME RESEARCH}

As the seminal articles suggest, the history of the subjective time concept is longstanding and rich, with momentum building around the idea that subjective time can extend our understanding of management phenomena. Yet, because the seminal articles lacked consensus on the conceptualization of subjective time, when subsequent articles incorporate "subjective time," it is not clear which conceptualization they are using. Therefore, to review management articles that explicitly or implicitly draw upon subjective time, we used the Google Scholar search engine to conduct a series of keyword searches derived from the concepts in Table 1 and augmented by our knowledge of relevant temporal concepts (e.g., temporal focus, temporal distance, temporal structures). After the initial generation of more than 90,000 results, we restricted our search first by publication outlet (i.e., published in a management journal with an impact factor of 3.0 or higher $)^{5}$, then by skimming article titles and abstracts for relevance. The culled list of 207 articles were read carefully, and we further excluded articles that were: a) unrelated to subjective time, b) purely methodological, or c) introductions to a special issue describing an article we had already retained.

The resulting 97 articles were coded by year published and primary research domain (e.g., cognition; strategy; organizational change). We also coded how each article accounted for the definition of subjective time (explicit, implicit, or not provided), level (i.e., intrasubjective or intersubjective), and citations of seminal time articles. Then, to extend our review beyond conceptualizations, we coded the use of mechanisms (i.e., concepts that explain how subjective time operates) and type of impact (i.e., conclusions made when using subjective time concepts). Lastly, we captured additional citations to consider, which generated 36 articles either published in outlets with an impact factor less than 3.0 (e.g., two special issues on time in Organization) or articles not initially retrieved by our keyword

\footnotetext{
${ }^{5}$ The list of journals was based on 2017 impact factors given that we conducted our search in 2018 .
} 
search. The final set of 133 articles was closely split between intersubjective $(\mathrm{N}=73)$ and intrasubjective $(\mathrm{N}=60)$ articles. $^{6}$

Across the sample, we found that subjective time is applicable to a variety of research areas in management and increasingly a topic of interest. A full $90 \%$ of the articles in our sample were published since 2000 , with $39 \%$ in the last five years alone. This exponential increase in recent work is also evidenced by its diffusion into numerous content domains in the sample -25 in all. The most common research domains were individual or team cognition $(\mathrm{N}=31)$, strategy $(\mathrm{N}=18)$, identity $(\mathrm{N}=17)$, organizational change $(\mathrm{N}=14)$, culture $(\mathrm{N}=$ 8), and leadership $(\mathrm{N}=7)$. Other domains were represented to a lesser extent $(\mathrm{N} \leq 5)$, such as organization theory and communication.

\section{What Subjective Time Is: Cognitive Actions}

Similar to the trend noted within the seminal articles, articles in our review continued to lack a consensus definition of subjective time. In fact, more than half used subjective time concepts without providing an explicit definition, making it difficult to draw conceptual comparisons across articles. In the absence of clear conceptualization, we coded articles based upon their primary use of one of the three actions in our definition-mentally traveling through time, perceiving time, and interpreting time. Table 2 lists the actions along with their prevalence by level (intersubjective or intrasubjective) and sample concepts, and in the section that follows, we address key insights that emerged in each action.

\section{INSERT TABLE 2 HERE}

Traveling through time. As stated earlier, traveling through time occurs when

\footnotetext{
${ }^{6}$ Sample articles are denoted by $*$ in our reference list. Counts by research outlet are available upon request.
} 
individuals or collectives retrospect or anticipate experiences at other points in time, mentally moving back and forth across the past, present, and future. Dane and George (2014) describe such cognition by explaining how “...we frequently depart from the present moment and consider events outside clock time" (p. 181). Articles that addressed mental time travel comprised about half of the sample, such as Schultz and Hernes (2013) who examine identity reconstruction in the present moment by evoking memories of past identities and articulating claims for future identities. Sample concepts as shown in Table 2 include mind wandering, future selves, organizational remembering, and forgetting. Thus, a clear characteristic of time travel articles is subjectively "visiting" the past and future within the current moment.

Time traveling articles also demonstrated the importance of relationships among the past, present, and future that are recurrent. By highlighting cyclicality and repetition, these articles often refer to concepts such as reconstructing (e.g., Comi \& Whyte, 2018; Suddaby \& Foster, 2017), recreating (e.g., Kimberly \& Bouchikhi, 1995), reconstituting (e.g., Hatch, 1993), or recrafting (Shipp \& Jansen, 2011). ${ }^{7}$ For example, Ibarra and Barbulescu (2010) suggest that self-narratives, composed of selected stories from the past, present, and future, "help people revise and reconstruct identities during work role transitions" (p. 135, italics added). As such, time travel happens over and over as individuals and collectives repeatedly consider the past and future in the present moment.

Although the time traveling action appeared almost equally across the intersubjective and intrasubjective levels, the past and future time frames were differentially emphasized by level. As implied by the balance of past versus future concepts in Table 2, studies at the intersubjective level addressed traveling to the past twice as much as the future, driven by topics such as organizational memory and rhetorical history (e.g., Anteby \& Molnar, 2012; Bordia, Restubog, Jimmieson, \& Irmer, 2011; Hatch \& Schultz, 2017; Rowlinson, et al.,

\footnotetext{
${ }^{7}$ See terms beginning with "re-" in the Appendix for further details.
} 
2010; Walsh \& Ungson, 1991; Ybema, 2014). For example, in the domain of organizational change, Suddaby and Foster (2017) describe how organizations intentionally reconstruct history by rhetorically bracketing and labeling past experience. Conversely, studies at the intrasubjective level addressed traveling to the future four times as much as the past, highlighting topics such as affective forecasting (Dane \& George, 2014; Dunn, Brackett, Ashton-James, Schneiderman, \& Salovey, 2007), future-oriented cognition (Rudolph, Kooij, Rauvola, \& Zacher, 2018; Strobel et al., 2013), and pragmatic prospection (Baumeister et al., 2016). Therefore, despite the possibility for time travel in both directions, there is an imbalance of findings that are mostly siloed by level. The field has fewer insights about how collectives engage with the future or how individuals engage with the past, which suggests that each level has overlooked meaningful time frames that can inform present experiences.

Interestingly, studies emphasizing the past or future (at either level) frequently called for future research to address whichever time frame had been excluded. For example, in discussing organizational change scholars' emphasis on the past, Ybema (2014) called for attention to "imaginings of the future alongside re-renderings of the past... why restrict our analyses to narrative representations of the past?" Such calls sound quite similar to the frequent admonishment that cross-sectional studies should conduct more longitudinal research. In both cases, researchers are potentially focusing on the more accessible or comfortable time frame and encouraging others to do the rest. To wit, only a small set of papers addressed traveling both forward and backward across time. However, they were primarily from researchers who purposely studied time by adopting a holistic view of the subjective past, present, and future (e.g., Schultz \& Hernes, 2013; Shipp \& Jansen, 2011).

What is missing, then, is the awareness and synthesis of complementary research emphasizing past and future, as well as an understanding of the benefits of studying the past, present, and future simultaneously. As Baumeister et al. (2016) noted, focusing on only one 
or two time frames overlooks the meaning that emerges when all three time frames are addressed. For example, in a past/present study, Ravasi and Schultz (2006) demonstrated that retrospective rationalization of past organizational culture shapes sensemaking around changes that threatened organizational identity. However, such sensemaking is not only pastfocused. It also can extend into the future when people simultaneously consider all three time frames to make sense of identity change (Dahm, Kim, Glomb, \& Harrison, 2019; Schultz \& Hernes, 2013). In this case, a comprehensive consideration of identity across time- from the past to the present to the future - provides greater clarity and can extend the intersubjective emphasis on the past. We conclude that integrative questions that intentionally address all three time frames should be developed for time traveling studies, regardless of level.

Perceiving time. The perceiving time action reflects individual and collective construal and communication of the configuration of time itself using schemas, mental models, and temporal structures. Studies using this action comprised about a quarter of the sample and refer to the creation of temporal formats to perceive time's structure (e.g., cycles, routines, and time horizons as shown in Table 2), which help individuals and collectives to better use time. For example, Lin, Shi, Prescott, and Yang (2019) demonstrate that top managers' long-term orientation creates "temporal referent points," which serve as anchors for future perceptions that inform strategic decision-making. In contrast to the time traveling studies, which highlight recursively revisiting the past or the future, perceiving studies identify temporal structures representing the past, present, and future to subjectively organize what could otherwise be perceived as ambiguous. As such, there was relatively equal emphasis across all three time frames.

Notably, approximately one-third of the perceiving time articles relied on an event time characterization of subjective time. Whereas time travel articles equally reflect other forms of subjective time (i.e., socially constructed time, psychological time, and duration of 
time), perceiving time studies were different such that temporal mental models, temporal structures, and temporal activities frequently followed the rhythm of events rather than the clock or calendar. For example, Dougherty and colleagues (Dougherty, Bertels, Chung, Dunne, \& Kraemer, 2013) define event time pacing as "that which uses unpredictable occurrences of...events to regulate attention and effort, coordinate activities, and gauge progress" (p. 234). The emphasis on event time in perceiving studies demonstrates that time can be crafted in ways that completely diverge from, or even contradict, objective time. Such crafting of the structure of time itself seems to benefit individuals and collectives as they operate within the ambiguity of an organization's temporal cues.

Perceiving time studies also were more prevalent at the intrasubjective rather than the intersubjective level (as reported in Table 2). Intrasubjective studies highlighted topics such as individuals' perception of deadlines (Waller, Conte, Gibson, \& Carpenter, 2001), the anticipated ending of team projects (Bakker, Boros, Kenis \& Oerlemans, 2013), and individuals' temporal depth (Bluedorn \& Jaussi, 2008; Das, 2004; Das \& Teng, 2001). For example, Nadkarni, Chen, and Chen (2016) describe how "executives mentally create their own 'temporal zones' (e.g., short-term vs. long-term) when deciding on strategic actions, irrespective of the actual environment they face..." (p. 1135). Similarly, temporal mental models emerge when group members agree about the subjective structure of their individual perceptions of deadlines, pacing, and sequencing (Mohammed, Hamilton, Tesler, Mancuso, $\&$ McNeese, 2015). In contrast, fewer intersubjective articles emphasized the perception of time at the collective level. However, those that did referred to time structures (Berg Johansen \& De Cock, 2018), temporal settlements (Kaplan \& Orlikowski, 2013; McGivern, et al. 2018), and organizational routines (Howard-Grenville, 2005; Miettinen \& Virkkunen, 2005).

We speculate that intersubjective concepts about temporal perception could be less 
prominent because it is difficult to build collective consensus about time's structure across the variety of individual perceptions. Even so, intersubjective scholars have an opportunity to build upon the rich findings at the intrasubjective level, particularly the influence of one or more individuals' perception of time (e.g., CEOs or change agents) on collective time structures. Similarly, intrasubjective scholars are well-positioned to consider the reciprocal relationship between the two levels over time, such as the influence that collective constructions of time have on individual perceptions (e.g., how organizational routines shape individuals' perceptions of deadlines), which then feed into subsequent social constructions (e.g., how people's perceptions of deadlines subsequently influence organizational routines). The lack of integration across levels is an important oversight because individuals can only be understood within the context of their social environment, and collective contexts can only be understood by accounting for the individuals within (Orlikowski \& Yates, 2002).

Although uncommon, a few studies in the sample did incorporate both levels, and in so doing, added value. For example, by examining temporal differences of individual team members as well as team leaders, Mohammed and Nadkarni (2011) were better able to predict team performance. Our point here is less about categorizing articles as intersubjective or intrasubjective (as we did to review these articles) and more about how the psychological and sociological aspects of subjective time are not, and cannot be, independent. The future of research on perceiving time is about blending and integrating collective and individual experiences to capture their concurrent perceptions.

Interpreting time. The final action, present in approximately a quarter of the reviewed articles, represents research about individual or collective interpretation of time itself in terms of meaning, quality, or significance. Whereas the perceiving time action addresses the awareness of time's structure, the interpreting time action draws attention to the meaning underlying these perceptions of time, particularly the sharing of significance with others 
(Ballard \& Seibold, 2006). Concepts from Table 2 (e.g., interpreting time as the right moment, Rämö, 2004; or connected time, Reinsch, Turner, \& Tinsley, 2008) represent individual and collective interpretation of time as it is being experienced. For example, Dawson (2014) states that "...temporality in the way we give meaning and understanding to the present in relation to our memories of the past and expectations of the future (subjectivities of human experience) is central to understanding the processual and contextual nature of changing organizations" (p. 301).

Like the perceiving time action, one-third of interpreting time articles preferenced an event time viewpoint in which events rather than the clock shaped different interpretations of time. For example, Granqvist \& Gustafson (2016) describe how “...events per se do not result in change; for this to occur, actors need to construct events into issues and make them meaningful to various stakeholders" (p. 1029). Obtaining meaning from events is useful because it can lead to positive insights and outcomes. For example, Staudenmayer, Tyre, and Perlow (2002) found that rhythm-changing events ("temporal shifts") led to the resolution of entrenched issues. Most event time articles emphasized some form of positive change by people interpreting and responding to the meaning of events (e.g., Slawinski \& Bansal, 2012; Staudenmayer et al., 2002).

Interpreting time studies also appeared consistently across the past, present, and future time frames. However, as reported in Table 2, interpretation was by far more prevalent in articles at the intersubjective level, highlighting the importance of shared interpretation in topics such as intersubjective sensemaking about change (Balogun \& Johnson, 2005), temporal spans in talk (Forray \& Woodilla, 2002), and the continual construction and destruction of meaning (Gray, Bougon, and Donnellon, 1985). In contrast, the few interpretive concepts at the intrasubjective level addressed more individualized topics such as temporal responsiveness (Blount \& Janicik, 2001) or time scarcity (DeVoe \& Pfeffer, 2011). 
Here, scholars emphasized how individuals developed their own interpretations about the personal significance of work experiences.

Yet, consistent with the time traveling and perceiving time actions, there was little cross-pollination across levels to explain individual and collective co-interpretation of time. This was particularly detrimental to intrasubjective scholars who, through their lack of attention to this topic, have missed opportunities to build upon the many intersubjective discoveries to date. Further, beyond a simple dearth of intrasubjective studies, theoretical lenses were differentially employed across levels. For example, studies of temporal interpretation at the collective level frequently used the sensemaking framework, relying on shared and constructed interpretations of time and change (e.g., Jansen, 2004). In contrast, when sensemaking was used in intrasubjective studies, it was typically employed in a cognitivist sense whereby individuals interpreted temporal cues on their own (e.g., Methot, Lepak, Shipp, and Boswell, 2017). Our point is that we have yet to understand fully the significance of interpreting time at the intersection of collective construction and individual cognition. We doubt the causal arrow of interpreting only travels downward from organizational interpretations to the individual. More likely, there are also instances in which individual interpretation can shape organizational interpretation (i.e., cognitive sensemaking that builds to a social construction). Scholars must jointly consider both individual and collective interpretations to truly understand the significance of time at work.

Overall insights about conceptualizations. Although the three subjective time actions described above provide insight into what subjective time is, the research remains siloed by level and time frames. In fact, most articles emphasize conceptualizations that are either intersubjective (i.e., sociological) or intrasubjective (i.e., psychological), rarely informing or incorporating both levels. Similarly, different time frames (e.g., past and future) are sometimes differentially emphasized across these levels. Neither of these approaches to the 
literature is inherently wrong - they are merely incomplete. This siloed understanding allows for only a partial view of the holistic nature of subjective time, in much the same way as blindfolded individuals describe an elephant by examining the varied constituent parts. For example, focusing only on collective sensemaking fails to capture how the individuals themselves make and give sense to collective actions. Alternatively, simply taking account of an organization's history is not sufficient for understanding how it informs the organization's current situation or its ability to achieve future ambitions. Thus, more research is needed that examines individuals' and collectives' joint experience of the past, present, and future.

Beyond silos based on level and time frame, there were clear divisions among the three cognitive actions. Looking across time traveling, perceiving time, and interpreting time, most articles were easy to code in only one action, meaning that scholars typically speak to one aspect of subjective time without addressing other actions. Yet, in the few articles in which a secondary action was employed, it provided greater insight. For example, in theoretical research on institutional change, Gray, Purdy, and Ansari (2015) used both time traveling and interpreting time to explain how collective interpretations of the past change and become a system of collective meaning, which then shapes subsequent collective interpretations. Also exploring institutional change, Granqvist and Gustafsson (2016) were one of the few who combined perceiving and interpreting time to understand actors who wish to "construct, navigate, and capitalize on timing norms in their attempts to change institutions" (p. 1009).

Notably, one article emerged that used all three actions (Jordan, Ferris, and Lamont, 2019). Building upon Cojuharenco, Patient, and Bashshur (2011), who employed two actions (time traveling bolstered by perceiving), Jordan and colleagues (2019) developed a framework that addressed cognitive biases in temporal distance (i.e., perceiving time) that influence reinterpretation (i.e., interpreting time) of both past and anticipated experiences of 
justice (i.e., time traveling). By using all three actions, they were able to explain that human resources initiatives do not uniformly generate positive outcomes because of individualized experiences with time travel, perception, and interpretation. Combined, these exemplar studies suggest that cross-pollinating across the three actions adds tremendous value and insight. Researchers must incorporate more than one subjective time action where feasible to broaden our understanding of organizational phenomena in subjective time.

\section{How Subjective Time Operates: Mechanism Functions}

Beyond reviewing the cognitive actions that help to explain what subjective time is, we also examined mechanisms that account for how these subjective time concepts operate. That is, subjective time mechanisms are the processes by which the three actions of traveling through, perceiving, or interpreting time transmit their effects. For example, an individual may time travel to the past or future but we know little about how such time travel actually works. A recent review by Tang et al. (2020) states that subjective time mechanisms have remained largely in a black box, indicating that such a review is essential. Yet classifying mechanisms across studies is challenging because scholars' identification of a particular mechanism is not always explicit, ${ }^{8}$ and many different terms have been used to refer to similar mechanisms. In fact, our initial coding included more than 50 different terms, which we subsequently refined and grouped into twelve clusters nested within three broader functions provided in Table 3. These three functions describe how mechanisms are used and the associated time frames in which they operate: a) attending to the past, present, or future, b) preparing for the future, and c) comprehending past, present, and future. As we will outline below, researchers need to be more cognizant of the relevant function and cluster, and more explicit and strategic in identifying specific subjective time mechanisms in order to

\footnotetext{
${ }^{8}$ Interestingly, researchers who implicitly use subjective time mechanisms may not even realize that subjective time concepts are involved.
} 
shed light into the black box between actions and impact.

\section{INSERT TABLE 3 HERE}

Attending to the past, present, and/or future. As shown in Table 3, five clusters of mechanisms comprise this function, which refers to processes that selectively direct attention to the past, present, or the future in the present moment. Based on the Latin roots ad("toward") and tendere ("to stretch," i.e., one's mind), these mechanisms are anchored in the drive to understand the relevance, emphasis, or influence of experiences from particular time periods. Not surprisingly, attending mechanisms are most commonly associated with the time traveling action. However, more than the simple act of retrospecting and anticipating, the attending mechanisms translate these cognitions into outcomes by allowing individuals and collectives to process experiences over time.

The first cluster, focus of attention, reflects the direction of cognitive attention to the past and/or future (i.e., time travel) and functions by either increasing or filtering out information in the present moment. Focus of attention is far more common in intrasubjective studies, primarily due to temporal individual differences such as temporal focus (e.g., the salience of the past, present, and future for job attitudes, Shipp et al., 2009; citizenship behaviors, Strobel et al., 2013; and decisions, Gamache \& McNamara, 2019) and time horizon/temporal depth (e.g., the temporal distance of one's thoughts as leading to strategic planning and risk-taking, Das, 1987; Nadkarni et al. 2016). Only a few studies have examined corollaries at the collective level, such as Gibson, Waller, Carpenter, and Conte (2007) who found that variation in teams' time perspectives help them more quickly create and transfer knowledge. Overall, focus of attention helps people to process experiences over time by attending to the most adaptive and beneficial time frames. 
A second attending cluster is temporal comparison, which functions as an evaluation of the present by comparison with the past and/or future. Here, individuals and collectives assess current experiences by contrasting them to what they recall experiencing in the past and/or what they anticipate in the future (Albert, 1977). For example, collectives make such contrasts when people "derive a sense of collective self...by making temporal comparisons" (Ybema, 2010, p. 494). Similarly, at the intrasubjective level, Strauss, Griffin, and Parker (2012) write, "When individuals compare their future work self with their current self, they identify discrepancies that form the basis of self-directed behavior to bring about their desired future" (p. 582). Attending to these contrasts not only provides an evaluation over time, it can motivate action based on perceived discrepancies (Schultz \& Hernes, 2013).

Temporal influence describes affective reactions to experiences in the past (e.g., nostalgia, rumination) or future (e.g., worry, hope). Present-day reactions to retrospections and anticipations help individuals attend to relevant experiences from other points in time. For example, retrospecting past experiences can influence present day outcomes through collective memory (Anteby \& Molnar, 2012), loss (Wolfram-Cox, 1997), and legacy (Eury, Kreiner, Trevino, \& Gioia, 2018). However, anticipating the future also provides temporal influence as seen in studies of affective forecasting (Dane \& George, 2014) or future selves (Hershfield, Cohen, \& Thompson, 2012). Thus, temporal influence functions by attending to past or future emotions because such reliving or pre-living promotes current actions.

Another attending cluster, learning (although limited in the sample), referred exclusively to attention directed to the past/present. Here, time travel allowed individuals and collectives to search past experiences for lessons to be used in the present. For example, some studies demonstrated how executives' ability to learn from past experiences facilitates organizational development (Kimberly and Bouchikhi, 1995) and strategic decision making (Gamache \& McNamara, 2019). Learning also may occur intrasubjectively via observation, 
experimentation, or socialization, such as when individuals learn from past experiences to shape their ongoing identities (Ibarra, 1999) or to facilitate role transitions (Ashforth, 2012).

The final attending cluster is accumulation, which is also strictly focused on past/present and represents the process by which past experiences build or amplify over time before reaching a threshold. Although the concept is certainly not new, it was found in only a few recent studies. For example, Jansen and Shipp (2019) found that individuals' retrospected misfit experiences built up to a breaking point, necessitating action such as a job change when such accumulation was recognized. Accumulation also functions intersubjectively, such as how cumulative past organizational experiences inform executives' strategic responses (Nadkarni et al., 2016), or micro-processes amplify to create institutions that break frame from the past (Gray et al., 2015).

Overall, the attending mechanisms demonstrate the variety of ways that attention to the past, present, and/or future allows individuals and collectives to presently evaluate and act upon retrospections and anticipations. Given that these mechanisms were commonly found in time traveling studies, it suggests that attending mechanisms function primarily as a vehicle for mentally visiting the past or future rather than perceiving the structure of time or interpreting the meaning of time itself. Yet despite their ability to consider both past and future, studies typically emphasize one direction or the other with purely past/present mechanisms (i.e., learning and accumulation) less understood. As we elaborate below, future scholars should consider both past/present and present/future simultaneously.

Preparing for the future. Four clusters of mechanisms function exclusively based on perceptions of the present and the future. These preparing mechanisms demonstrate how people perceive the future as unknown and ambiguous and therefore use the present to prepare, a concept that stems from the Latin roots prae- ("before") and parāre ("to make ready"). That is, the clusters described here refer to the ability to not only think about future 
expectations (i.e., the attending mechanism above) but also to construe the future in ways that facilitate current planning and action. Thus, preparing mechanisms build upon the time traveling action to identify relevant anticipations but predominantly derive from the perceiving time action whereby people construe the future to shape present actions.

The first and most used preparing cluster is projection, which explains how people perceive future expectations for the purpose of informing present efforts. This cluster addresses a number of future-oriented cognitions and behaviors such as planning, envisioning, and goal pursuit that function by allowing the future to direct present choices. For example, Zhang, Wang, and Pearce (2014) show that considering future consequences leads to better transformational leadership because it highlights long-term future impact. Projection was twice as prevalent in intrasubjective studies because, even when addressing intersubjective topics such as strategic planning or future time horizon (Das, 1987; Reilly, Souder, \& Tanucci, 2016), scholars tend to regard future projection as an individual action (i.e., an executive) rather than a collective one.

Temporal allocation is another preparing mechanism cluster that describes how individuals and/or collectives perceive and interpret temporal structures to enable both current and future performance. These temporal structures function by creating schedules (Mohammed et al., 2015), activity cycles (Ballard, 2008), or routines (Howard-Grenville, 2005). For example, Mohammed \& Nadkarni (2014) demonstrate how shared temporal cognitions such as schedules are essential for team performance when the team includes a mix of polychronic and monochronic members. Interestingly, temporal allocation was not widely used but was equally common across levels given that both individuals and collectives structure their time toward future goals.

The third preparing cluster is time awareness - the perception of time itself, whether the scarcity of time before a future deadline or the economic value of time today versus in the 
future. Time awareness was relatively less studied but found predominantly at the intrasubjective level, which makes sense because it functions through behaviors typically associated with individuals. For example, DeVoe and Pfeffer (2007) found that hourly pay makes individuals aware of the economic value of their time and therefore less willing to volunteer (see also DeVoe \& Pfeffer, 2011; Evans, Kunda, \& Barley, 2004). As another example, Waller et al. (2001) theorized that individuals' attention to the future increases awareness of deadlines, spurring more planning when future deadlines are salient.

Lastly, temporal construal is the mental representation of a future event based on its temporal distance from the present. When future events are perceived as closer to the present, they are construed in more detail (Trope \& Liberman, 2003), leading people to prepare for the future differently when they perceive it to be near versus far. This mechanism was relatively scarce and found predominantly in intrasubjective studies such as Das \& Teng (2001) who examined how individuals are risk-seeking or risk averse based on holding a long-term versus short-term planning horizon. Scholars also have examined how a stronger focus on the distant, abstract future leads to increased salience of distributive versus procedural justice (Cojuharenco et al., 2011). As such, temporal construal functions by preparing people for upcoming events and shaping the way they currently perceive the future.

Combined, these four mechanism clusters highlight the importance of preparing for the future in the present moment. Although projection was the most common, all of these future-facing mechanisms shed light on the processes by which people perceive and prepare for the future. We also noted that temporal awareness and temporal construal have been primarily examined at the individual level, yet these mechanisms may be helpful at the collective level to understand how organizations or institutions construe the future to drive current actions (e.g., in service of a global movement).

Comprehending past, present, and future. The final set of mechanisms differs from 
the previous two by simultaneously accounting for the past, present, and future in a process of comprehending. Based on the Latin roots com- ("completely") and prehendere ("to take hold of'), these three mechanism clusters function by connecting and fully understanding one's past, present, and future experiences holistically. Thus, although time travel is the building block that identifies relevant retrospections and anticipations, the comprehending function derives predominantly from the interpreting time action (i.e., explaining experiences as a whole).

The first comprehending mechanism is narrative - the sequencing and interpreting of the past, present, and future to form a coherent story. This cluster functions by addressing ways people utilize storytelling, temporal bracketing, and the subjective identification of trajectories and themes over time. These means of comprehension are fundamental instruments for individual cognition as well as collective organizing (Brown, Stacy, \& Nandhakumar, 2008). Narratives were primarily used in intersubjective level studies, such as when collectives tell stories to facilitate the understanding of organizational culture (e.g., Balogun \& Johnson, 2005; Bartunek \& Woodman, 2015; Gabriel, 1995), to create and transmit organizational memory (e.g., Adorisio, 2014), or to inform strategic moves (e.g., Haley \& Boje, 2014). However, narrative was used in some intrasubjective studies as well, such as when individuals create self-narratives to inform identity work following a role transition (Ibarra \& Barbulescu, 2010). Notably, some narrative studies placed more emphasis on the past than the future (e.g., Brown \& Humphreys, 2002; Maclean, Harvey, Sillince, \& Golant, 2014; Schrempf-Stirling, Palazzo, \& Phillips, 2016), indicating that the present interpretation of narratives can inform future actions but they are crafted more heavily from the recollected past.

The second comprehending cluster addresses meaning, which refers to an understanding of the significance of past, present, and future experiences. Interestingly, this 
mechanism was four times more common in intersubjective versus intrasubjective studies. Scholars primarily have focused on how collectives construct, transfer, or destruct meaning, typically to motivate behavior or change. For example, "managers [use] time not just as a simple linear measuring stick, but as a shaper of social reality and meaning" (Staudenmayer et al., 2002, p. 593; see also Gherardi \& Strati, 1988). Meaning is also applicable to national culture as different cross-cultural meanings of time shape time allocation (Levine, 2005) or knowledge transfer (Cunha \& Cunha, 2004). Thus, to comprehend and interpret past, present, and future experiences, people (especially collectives) search for significance and meaning.

Lastly, sensemaking refers to the social and/or individual process of interpreting using schemas about the past, present, and future. Although the literature historically has focused on retrospective sensemaking between the past and present (Maitlis \& Christiansen, 2014; Weick, 1995), emerging uses of this mechanism also address prospective sensemaking. Such sensemaking can occur at the intrasubjective level, such as Methot et al. (2017) who argued that individuals (dis)continue helping behaviors based on retrospective and prospective sensemaking. It also occurs at the intersubjective level, such as Brown et al. (2008) who describe the challenges of organizing in which "a basic shared storyline may be appropriated, modified and embellished by individuals to make idiosyncratic sense... of equivocal actions and outcomes" (p. 1052). Intersubjective studies also identified sensegiving and sensebreaking as additional mechanisms by which leaders influence their organizations.

As shown in Table 3, the comprehending mechanisms were some of the most commonly studied mechanisms in the entire sample. We were excited to find that such a holistic approach is widely evident in the literature, suggesting that the interpretation of experiences over time is particularly impactful for both individuals and collectives. Yet it is curious that one important mechanism for comprehension — meaning — was studied predominantly at the intersubjective level. Despite its potential importance for individuals, 
we know little about the process by which they ascribe meaning to their retrospections and anticipations. In the next section, we discuss this issue as well as key insights across all the mechanisms.

Overall insights about mechanisms. An abundance of mechanisms were found that explain how subjective time operates for individuals and collectives, providing several implications for future research. First, and most simply, Table 3 demonstrates the value of consolidating the variety of terms under each mechanism cluster to increase clarity and consistency in the study of these processes. Scholars cannot build upon others' discoveries if literature searches and meta-analyses fail to detect similar mechanisms housed in different literatures (e.g., “projection”, Dahm et al., 2019; Carlsen, 2006; Ravasi \& Schultz, 2006; versus “prospection”, Baumeister et al. 2016; Lord et al. 2015; Miettinen \& Virkkunen, 2005). Researchers are strongly urged to adopt the cluster labels from Table 3 to better consolidate mechanisms and build upon rather than duplicate others' discoveries. Literature reviews within each cluster may be warranted to further synthesize the many different terms and research domains represented.

Second, the three mechanism functions — attending, preparing, and comprehendingsimplify our understanding of how subjective time transmits its effects to outcomes. Researchers are encouraged to consider mechanisms that align with the underlying action(s). In other words, in researching phenomena involving subjective time concepts, rather than following the familiar practice of applying an existing analytic tool or mechanism (e.g., narrative) as the lens for the next research problem (i.e., the proverbial hammer in search of a nail), scholars should theoretically select a subjective time mechanism based upon the conceptual action(s) and mechanism function(s) underlying the research question. Is the study intended to examine the process by which people cognitively attend to the past or future, prepare for future experiences, or holistically comprehend experiences over time? 
These can be fundamentally different questions.

A third and related point is that mechanisms should address relevant time frames. We noted that overall, present/future mechanisms have been emphasized more in the reviewed studies. Yet the past/present mechanisms (e.g., learning or accumulation) are also an essential aspect of engaging with subjective time. Therefore, we encourage scholars to elevate the past to the same degree of importance as the present and future. One strategy to do so is by leveraging the comprehending mechanisms (e.g., meaning, narrative, and sensemaking), which naturally include all three time frames. Although not all studies using these mechanisms equally emphasize past, present, and future, these comprehending mechanisms potentially explain processes over time more thoroughly by examining the interrelationships among the past, present, and future. For example, research on the temporal aspects of communication typically focuses on construals of the present and future (e.g., whether time is scarce; Ballard \& Seibold, 2003). Yet if narrative and meaning were first applied as the foundation for comprehension, communication may be viewed instead as an ongoing story through which individuals search for meaning_-learning from and accumulating past experiences while also creating temporal construals in preparation for the future. As this example highlights, holistic mechanisms that address the past, present, and future are the most comprehensive way to explain how subjective time operates.

Lastly, there are opportunities to further explore combinations of mechanisms. Although most studies employed only one or two mechanisms, there was an interesting pattern to the use of multiple mechanisms. For example, narratives and sensemaking frequently co-occurred, and were accompanied by the mechanism of meaning, especially at the intersubjective level (e.g., Balogun \& Johnson, 2005; Gray et al., 1985). This implies that meaning may offer insights into other mechanisms as a foundational process of comprehension, potentially as a broader category that can subsume other mechanisms (e.g., 
the motivation for why individuals and collectives utilize sensemaking, narrative, temporal comparison, or temporal influence). Future research should explore meaning as a fundamental mechanism underlying the process by which subjective time operates. We return to this point in our discussion section.

\section{Why Subjective Time Matters: Types of Impact}

After reviewing conceptualizations and mechanisms, we shifted our attention to the impact of subjective time, that is, what changes as a result of incorporating subjective time concepts and mechanisms. We initially set out to review outcomes across studies and research domains, looking for common outcomes related to subjective time. However, we quickly determined that these outcomes were applicable primarily to the domains in which they were embedded. For example, Hatch and Schultz (2017) offer a fascinating study of how organizational historicizing creates organizational authenticity. Yet such an outcome is specific to this domain and not necessarily temporal. As a result, a review of subjective time outcomes felt premature given the state of the literature. Instead, we noted several domainspecific examples of subjective time outcomes throughout the body of the review, and use this section to review how scholars have utilized subjective time conceptualizations and mechanisms to generate insights about management. This form of impact demonstrates why subjective time matters for our field.

As shown in Table 4, three types of impact emerged to explain how scholars are using subjective time: a) applying subjective time concepts to existing domains; b) challenging implicit temporal assumptions; and c) improving the understanding of subjective time. Across these types of impact, scholars were able to identify new research questions, including novel insights within specific domains and fresh ideas about subjective time itself. As we will explain, as the study of subjective time has started to mature, scholars seem to be moving beyond common application tactics toward efforts that challenge existing assumptions (the 
downward arrow in Table 4). However, an improved understanding of subjective time has lagged the other two types of impact, which is ironic given that continual improvements in conceptualization underlie the application of subjective time and the questioning of its assumptions.

INSERT TABLE 4 HERE

Applying subjective time concepts to an existing research domain. Across both intersubjective and intrasubjective time and all three actions, most articles demonstrated impact by applying subjective time to an existing research domain (e.g., leadership, strategy, or organizational communication). Scholars used existing subjective time concepts and/or mechanisms to elucidate new research questions and insights, typically in a research area that had not yet considered subjective time. For instance, Dougherty et al. (2013) used subjective time in the form of event time pacing to better explain the dynamics and effectiveness of innovation. Beyond layering subjective time concepts onto an existing research stream, some authors also used the application tactic to contrast subjective time against objective time. For example, Dawson (2014) argued that incorporating subjective time into an understanding of organizational change better reflects how objective and subjective time are intertwined in practice (e.g., "lived through experiences"). Thus, the application approach shows how the lesser-known aspects of subjective time augment the better-known aspects of objective time.

Interestingly, empirical studies within this type of impact typically positioned subjective time concepts as influencing a pre-existing set of relationships or outcomes. Although this method of application is a good start to considering subjective time, scholars rarely considered antecedents of these same subjective time concepts (i.e., feedback loops from the outcome back to the subjective time concept). This finding suggests that when 
scholars have applied subjective time to an existing set of research questions, they rarely integrate that domain's findings back into an improved understanding of subjective time. For example, research applying the concept of CEO temporal focus to firm outcomes (e.g., Gamache \& McNamara; Nadkarni \& Chen, 2014) has not yet examined how firm success or failure can reciprocally shape a leader's temporal focus. This may be because temporal focus is typically viewed as a stable individual difference. Yet other studies show that temporal focus can change, either temporarily (from situational cues) or permanently (from significant experiences; e.g., Foo, Uy, \& Baron, 2009; Holman, Silver, Mogle, \& Scott, 2016; Rush \& Grouzet, 2012; Shipp \& Aeon, 2019). Therefore, questions remain about possible feedback loops from outcomes to subjective time concepts.

Overall, the application technique seems to be an effective and widely used first step for demonstrating the impact of subjective time in management research. However, the approach seems limited to date by its tendency to examine subjective time constructs solely as independent, moderating, or contextual variables. Thus, scholars should move beyond simple application tactics to predict what leads to changes in subjective time constructs.

Challenging implicit temporal assumptions within a research domain. The second type of impact is how scholars use subjective time concepts and mechanisms to challenge implicit assumptions within a research domain, which occurred in time traveling, perceiving, and interpreting studies. Momentum seems to be building around the identification of critical but hidden issues in the literature, with almost half of the articles in the sample portraying assumptions differently when the subjective time perspective is incorporated. Some of the assumptions identified were domain specific (e.g., mind wandering is not always detrimental; Dane, 2018; valuing time in an economic sense applies to all workers, not just those paid by the hour, DeVoe \& Pfeffer, 2007). However, across domains, there were three frequently challenged assumptions. 
One of the most prevalent in the sample, particularly for intrasubjective studies, was that phenomena presumed to be homogeneous are actually heterogeneous (i.e., individual or team variation). For example, Waller et al. (2001) demonstrated that deadlines are perceived differently by individuals, questioning the assumption that "teams" perceive and perform against deadlines. The main conclusion in these types of studies is that subjective time offers better insights by addressing temporal heterogeneity rather than assuming that all individuals and teams approach time in the same way.

A second assumption addresses how short-term and long-term perceptions of past/future are presumed to be the same but they actually differ. Like the first assumption, subjective time helps to identify variation in outcomes, but this second assumption moves beyond the categorical consideration of individuals versus collectives to focus on variation across time. Here, temporal distance to the past or future matters for people's time travel, perception, and interpretation of time, with different experiences in the short-term versus long-term. For example, Crilly (2017) found that executives who perceive that "we are moving to the future" direct attention to the near-term future (i.e., an extension of the immediate present), whereas those who perceive that "the future is approaching" direct attention to the more distant future. Questioning the assumption of differences between the short- and long-term is helpful because it demonstrates the value of adding subjective time onto objective time. By challenging implicit temporal assumptions that the "past" and "future" are unitary concepts, the focus instead becomes how retrospections and anticipations differentially shape current outcomes based on their distance to the present.

The final assumption is the idea that phenomena presumed to be stable are actually dynamic. This assumption was addressed by scholars such as Howard-Grenville (2005) who showed that seemingly stable routines can change when individuals and collectives draw upon perceptions of the present and future. Using subjective time to challenge the assumption 
that an established phenomenon is stable is particularly interesting because this assumption inherently seems like an objective time question—stability versus change. However, in studies within the sample, it was the impact of subjective time that allowed scholars to uncover how change occurred in objective time - via subjectively traveling through, perceiving, and interpreting time.

In sum, using subjective time's concepts and mechanisms to question these three assumptions was widely applied to a variety of research domains and across all three actions. Although not as widespread as the application of subjective time, the questioning assumptions technique seems to be building momentum as it offers novel views of existing research questions. That said, some studies did not specify that these assumptions were specific to subjective time. Perhaps because of the conceptual confusion noted earlier, some scholars simply referred to "time" without indicating that they had meant subjective time specifically. Given that the second and third assumptions could be potentially framed as objective time topics, subjective time scholars need to explicitly identify when the assumptions under question are related to subjective time, objective time, or both. Otherwise, scholars will continue to muddy the waters of impact from these two forms of time.

Improved understanding of subjective time. The last type of impact was the least prevalent in the sample but addressed the importance of an improved conceptualization of subjective time itself. Scholars here further refined the definition, boundaries, and processes associated with subjective time concepts and mechanisms. This type of contribution occurred primarily within the perceiving and interpreting actions related to intersubjective articles, suggesting that the field continues to improve the understanding about collectives' engagement with subjective time. However, less has bene done to advance the understanding of subjective time for individuals, particularly the many subjective time concepts related to time traveling. 
Most often, deepening the understanding of subjective time occurred through the identification of new subjective time concepts. Examples include organizational time (the plurality of internal times within an organization; Cunha, 2004a; Gherardi \& Strati, 1988); time visions (different perceptions of time within a team or culture; Saunders et al., 2004); or temporal work (the linking of past, present, and future interpretations to facilitate strategic action; Kaplan \& Orlikowski, 2013). For example, Kaplan and Orlikowski’s introduction of temporal work explains how managers deal with uncertainty in strategic decisions by rethinking past experiences and revisiting present concerns to reimagine the future. This work contributes back to the subjective time literature by offering a new concept that deepens the understanding of subjective time itself.

Occasionally, instead of creating new concepts, scholars elaborated existing subjective time concepts with new perspectives, such as Van de Ven and Poole's (2005) identification of not one but four ways to study organizational change. Another exemplar in this regard is Suddaby and Foster (2017) who recently articulated how organizational history has been portrayed as unidimensional but could be viewed in four different ways: history-asfact, history-as-power, history-as-sensemaking, and history-as-rhetoric. These examples deepen the understanding of subjective time by identifying additional theoretical lenses through which existing concepts can be considered.

Overall, despite the importance of this type of impact, there was surprisingly less work on improved conceptualizations of subjective time compared to more basic application or questioning of key assumptions. This is interesting given the earlier observation that both the seminal articles and the sample articles continue to struggle with the right conceptualization. It seems that the literature as a whole has not made much empirical or theoretical progress in this regard, which is troubling if scholars desire a common foundation for subjective time research. Our position is that, if the field cannot agree upon an 
overarching conceptualization of subjective time, the application or questioning of key assumptions is simply premature.

Overall insights about impact. To make more progress, the study of impact needs to move beyond basic application to more frequent (and more diverse) challenging of assumptions, as well as deeper conceptualizations of subjective time itself. Nowhere was this lack of continued refinement more obvious than our discovery that subjective time concepts are rarely studied as outcomes. That is, we know little about the factors that lead individuals and collectives to engage with subjective time concepts and processes. The prevailing wisdom to date seems to point only to individual differences and situational cues (e.g., events) as triggers. Yet viewing subjective time as the outcome of interest provides additional directions to explore, such as how the conceptual actions of traveling through, perceiving, and interpreting time differentially begin and end, or how specific characteristics of events and change processes lead to greater (or lesser) use of subjective time concepts and mechanisms. For example, research has demonstrated that people mentally time travel outside the present moment about half of the time (Dane, 2018), indicating that subjective time is relevant during a large portion of one's day. However, is subjective time relevant during the other half of the day (i.e., when focused on the present moment)? Further, are there times when engaging with subjective time is harmful versus helpful?

Taking these questions for future research one step further, research also is needed on the mutual impact of objective and subjective time. Across the forms of impact, subjective time impacts management research because it clarifies outcomes and processes that objective time cannot explain. This is not a widely cited contribution of subjective time but one that we insist is critical. Whether in questioning key assumptions about stability versus dynamism or identifying new constructs, a focus on subjective time helps us to understand more deeply how individuals and collectives experience changes that occur through the passage of clock 
time, whether such change is real or perceived. Therefore, change over objective time can be understood only by examining the concurrent impact of subjective time. This implies that any study addressing the passage of objective time by necessity must include a concomitant accounting for subjective time. Given that longitudinal studies are on the rise in management (Shipp \& Cole, 2015) and objective time is potentially "a very limited conception" (Das, 2004, p. 268), future research must intentionally devote more attention to subjective time on par with attention to objective time. Subjective time needs to move beyond being the "other" time, to the crucial and fundamental concept on which objective time is based.

\section{NEW WAYS OF UNDERSTANDING SUBJECTIVE TIME}

Based on our review of the literature, it is clear that research on subjective time holds tremendous promise. Although greater awareness of subjective time is still needed to "increase the coherence and congruity" of our studies (Avital, 2000: 665), the exponential increase in articles over the last few decades suggests that the time is right to build a stronger foundation for the future. The insights from our synthesized and multidimensional definition of subjective time and its associated actions, the functional ways subjective time mechanisms operate, and the various forms of impact provide ample structure and direction to inform future research. By building upon these findings and providing a glossary of terms, we believe the field can finally move beyond the prolonged "temporal Tower of Babel" (Ancona et al., 2001: 527) to a more integrated and sophisticated understanding of the role subjective time plays in organizations.

\section{How to Account for Subjective Time in Organizational Research}

As shown in Table 5, scholars who are interested in introducing subjective time to a research domain that currently does not address it (including those that emphasize only objective time) can do so in a relatively straightforward, step-by-step fashion. First, they can hone in on one or more subjective time actions (traveling through, perceiving, and 
interpreting time) and levels (intersubjective and intrasubjective) relevant to their research interest (e.g., exploring subjective time travel among job applicants before a job interview). Second, they can select applicable mechanisms based on the study's purpose (i.e., attending, preparing, and/or comprehending) that underlie the phenomenon they seek to explain (e.g., attending to prior interview mistakes via learning and preparing for anticipated interview questions through projection). Ideally such a selection will entail a holistic view of past, present, and future (e.g., creating a narrative that weaves together past interview success with future preparations). Finally, scholars can consider which types of impact are most critical (i.e., application, questioning assumptions, and/or developing subjective time itself), being sure to move beyond simple application to a deeper and more profound understanding of subjective time (e.g., how does interview success change the direction, degree, and usefulness of traveling through time?). This step-by-step approach demonstrates how, with intentional effort, scholars can easily extend existing research areas with the subjective time perspective.

\section{INSERT TABLE 5 HERE}

Table 5 also provides direction for those interested in making greater contributions to their research domain by expanding the usage of subjective time. We invite scholars, particularly authors cited in our study who have already begun to make these contributions, to take stock of their own domains perhaps with formal reviews, critically assessing coverage of subjective time actions, mechanisms, and impact. After reviewing progress, these researchers can push their domains to leverage relevant but underdeveloped aspects of subjective time such as multiple levels and actions, all three time frames, and deeper types of impact to generate new research questions. These advances can benefit their specific domains as well as inform the broader body of subjective time research. 
Finally, for those who would like to contribute directly to the understanding of subjective time itself, we outline three substantial challenges that create new ways of considering subjective time. In the remainder of this section and the far right column of Figure 5, we recommend that future research explore: the role of meaning in subjective time; where event time fits within the objective-subjective time continuum; and the connections and frictions between subjective and objective time.

\section{Contemplate Subjective Time as a Fundamental Search for Meaning}

"Those who have a 'why' to live, can bear with almost any 'how'."

-Viktor E. Frankl, Man's Search for Meaning, 1946/2006

The first challenge for future subjective time research highlights the importance of meaning relative to subjective time experiences. Throughout the review, we noted the repeated appearance of the meaning concept as a search for significance in one's experiences through subjective time. Although most evident as a cluster within the mechanisms section, meaning also was found in the conceptualization section, primarily within the interpreting time action. In fact, upon revisiting our own writing in this manuscript, we found over 70 uses of the term, more than double the appearance of other common mechanisms like sensemaking or narrative. Given the pervasiveness of meaning, this review led us to conclude that when people travel through, perceive, and interpret subjective time, they are inherently seeking meaning in a manner that objective time cannot provide. Returning to the origins of subjective time, one of St. Augustine's main points is that memory, perception, and anticipation essentially define human existence. Thus, subjective time itself may be a philosophical view of time as well as a broader, more fundamental search for meaning as noted by the Frankl quote above. That is, individuals travel through, perceive, and interpret time because they want to understand why - why their past experiences have unfolded in a particular manner, why their current experiences are materializing as such, and why their future will continue on the same trajectory (or not). Thus, meaning may be not just another 
mechanism, but instead the primary motivation underlying all subjective time concepts and mechanisms, critically used to understand significance, salience, and purpose.

For example, events such as the COVID-19 pandemic indicate that people have questioned how they think about and use time based on interpreting the significance of their daily experiences. Although extreme, this example demonstrates how people's creation of temporal structures such as a "quarantine routine" (New York Times, March 30, 2020) create meaning when regular routines are disrupted. These pandemic experiences actually demonstrate the importance of all three conceptual actions: interpreting time (i.e., "what does a 'workday' mean in the absence of the typical office experiences?'); perceiving time (i.e., “why does time pass more quickly/slowly when working from home?”); and time travel (e.g., "will the meaning of my job change pre-pandemic versus post-pandemic?").

That said, despite the prevalence of meaning in subjective time research, it is curious that the concept has been applied differently in various literatures. In the sample, some management scholars used the term "meaning" interchangeably with sensemaking (e.g., Höllerer, Jancsary \& Grafström, 2018) whereas others simply used it in a colloquial sense (e.g., referring to meaning without citing a specific concept; Wolfram-Cox, 1997). To wit, despite philosophers pondering the question for centuries (cf. Muldoon, 2006), scholars have recently acknowledged that meaning continues to be hard to define and understand (King, Heintzelman, and Ward, 2016; Lepisto \& Pratt, 2017). Therefore, if meaning is truly a foundational motivation for how people comprehend and act upon their experiences within subjective time, future scholars must advance its conceptual development by specifying what is (and is not) meaning, particularly in a temporal sense. For example, management research has equated meaning with significance and purpose (Grant, 2012; Pratt \& Ashforth, 2003; Rosso, Dekas, \& Wrzesniewski, 2010), both of which are time-free. However, meaning also has been associated with the detection of a reliable pattern (Heintzlman, Trent, \& King, 2013) 
or with enduring values and ultimate aspirations (Carton, 2018), both of which highlight the importance of retrospection and anticipation—-key subjective time concepts. Scholars must establish how central subjective time is to the concept of meaning because, as we noted earlier, its temporal dimensions may establish the foundation for all subjective time questions.

\section{Untangle the Complexity of Event Time as Both Subjective and Objective}

"The events in our lives happen in a sequence in time, but in their significance to ourselves they find their own order, a timetable not necessarily--perhaps not possibly-chronological...time as we know it subjectively is often the...continuous thread of revelation."

-Eudora Welty, One Writer's Beginnings, 1983

Our review carefully focused on subjective time separate from (and often in contrast to) objective time. However, there were several times where the demarcation between the two was less clear, which we refer to as the "murky middle" of the objective-subjective continuum of time. For example, Van de Ven and Poole (2005) offered a typology of four ways that time has been conceptualized in organizational change research. Two of their quadrants (Approach I-Variance Study of Change and Approach III-Process Study of Organizing) explicitly refer to objective or subjective time, respectively. The other two quadrants (Approach II-Process Study of Change and Approach IV-Variance Study of Organizing) emphasize succession of events and temporal patterns, respectively, blending objective and subjective time. Their article highlights that concepts situated at the intersection of objective and subjective time need additional conceptual attention. With this in mind, our second challenge for future research calls for additional clarification of the concept of "event time."

Throughout the review, and in Van de Ven and Poole's (2005) Approach II, we encountered many articles describing event time in ways that either blurred the line between objective and subjective time or were agnostic as to which form of time was intended. For 
example, in both the seminal and full review, some papers portrayed event time as truly subjective-interpreting and imbuing events with meaning, which was generally created through social construction (e.g., Perlow, 1999; Saunders et al., 2004). However, in other papers, event time seemed to be subjective only to the extent that it provided an alternative organizing mechanism to the clock or calendar (e.g., Clark, 1985; Levine, 2005). In these cases, event time is less about mental time traveling or interpreting time, and more about creating subjective temporal structures that organize and synchronize work across objective time. This lack of specificity in terms of its "subjectivity" implies that the latter conceptualizations of event time overlap with objective time.

The next temporal mountain to climb is a more detailed examination of event time in relation to both objective and subjective time. The concept is both objective and subjective, with event time as an objective concern operating in distinct and different ways from event time as a subjective concern, such as Welty's quote above about the chronology of events versus the "continuous thread of revelation." As such, and in contrast to the previously inaccurate labeling of "event time" as a unitary concept, it may be more accurately portrayed as two different concepts that require different labels and definitions. However, future research also should consider that event time could be a distinct, third type of time with unique characteristics. That is, by being neither purely objective nor subjective, event time may be wholly different and therefore distinct from the objective/subjective continuum. Such clarification would help to elaborate the subjective time conceptualization established in this paper as well as inform our understanding of the objective-subjective time continuum.

This challenge is particularly timely and important given that events have become a priority in recent management research, particularly with the creation of event system theory (Morgeson, Mitchell, \& Liu, 2015). These authors propose that the world is composed of events rather than things, such that scholars should focus on the novelty, disruption, and 
criticality of events. However, whereas Morgeson et al.'s events can be characterized as novel, disruptive, or critical, event time in subjective time studies is usually portrayed as cyclical, predictable, and routine. Thus, events under the umbrella of event time in our sample may be less impactful (or even irrelevant) when viewed through the lens of event system theory. Additional work on event system theory should account for these recurrent events as noted in event time. Whereas the theory primarily focuses on exogenous or onetime events instead of repeated event cycles, we urge greater attention to the conceptual linkages between events and event time as a subjective time concern. A better understanding of event time itself is urgently needed as event-based research is poised to grow dramatically.

\section{Unravel the Paradox of Objective Time as Both Interdependent With and Dependent Upon Subjective Time}

"During the act of knowledge itself, the objective and subjective are so instantly united, that we cannot determine to which of the two the priority belongs. There is here no first, and no second; both are coinstantaneous and one."

-Samuel Taylor Coleridge, Biographia Literaria, 1817

The third challenge we offer lies at the intersection of subjective and objective time. Here, we critique the past tendency to relegate subjective time as the secondary "other" time against the more dominant objective time. Instead, we radically suggest that subjective time is the foundation for objective time. This line of thinking began when finding concepts throughout the review, and in Van de Ven and Poole's (2005) Approach IV noted above, that blended objective and subjective time. For example, concepts such as synchronization and duration, or mechanisms such as learning and accumulation may be subjectively experienced and interpreted, yet they simultaneously require the actual passage of time to unfold.

Related, in many studies, there was some blurriness between "temporal constructs" (cf. Conte, 2007) that represent or measure time (e.g., temporal depth, temporal focus), and "dynamic constructs" (cf. Luciano, Mathieu, Park \& Tannenbaum, 2018) that change through the passage of objective time (e.g., team performance, identity). Articles in the sample did not 
explicitly draw this distinction, yet this bifurcation highlights unstated assumptions about the extent to which these constructs represent both objective and subjective time, as well as the complexities associated with studying both forms of time more generally. For example, we found that scholars studying time itself typically emphasized temporal constructs (e.g., temporal individual differences; Mohammed \& Harrison, 2013), whereas those coming from the perspective of a research domain privileged dynamic constructs (e.g., cultural dynamics; Hatch, 1993; dynamics of strategic change; Kunisch et al., 2017; dynamics of citizenship behaviors, Methot et al., 2017). This tension echoes earlier concerns about a divide between "research on time" versus “time-related research" (Lee and Liebenau, 1999, p. 1035), or "time as a focal construct" versus "time as a medium for change" (Shipp \& Cole, 2015, p. 239).

What is critical to note is that any dynamic phenomenon that changes over objective time is simultaneously perceived and interpreted in a subjective sense. Therefore, subjective time necessarily shapes how objective changes (if there are such things) are construed. However, the field is lacking sophisticated ways to integrate these interdependencies. As a starting point for facilitating this integrated view, we offer Figure 1, which portrays objective time along the $\mathrm{X}$-axis (as is conventional), with subjective time embedded within objective time. In other words, in any moment of objective time, whether the immediate "present" or the extended "long present" (Kim, Bansal, \& Haugh, 2019), individuals or collectives can mentally time travel to consider the past, present, or future. Consistent with the dualism shown in the figure, future research should move away from purely dynamic mindsets that only account for objective time and instead enact a temporal mindset that addresses both objective and subjective time. That is, rather than studying objective or subjective, future scholars should embrace the paradox of objective and subjective (cf. a "completely temporal view," Shipp \& Cole, 2015; see also Slawinski \& Bansal, 2017). In this way, scholars can 
acknowledge the simultaneous and underlying influences of both types of time, including points of connection and friction between the two. Our review suggests that some scholars have started this conversation (e.g., Dawson, 2014; Kaplan \& Orlikowski, 2013; Orlikowski \& Yates, 2002; Slawinski \& Bansal, 2012), and our event time challenge above continues it, but more can be done to address research questions that fully integrate objective and subjective time.

\section{INSERT FIGURE 1 HERE}

Going one step further, future scholars should consider that, in addition to the paradox of objective and subjective time, we have uncovered a hierarchical relationship in which subjective time seems to be the foundation upon which objective time is experienced. Figure 1 indicates that, although objective time is continually passing, one's present is always viewed through the lens of subjective time. Put another way, without the effect of subjective time, there is no effect of objective time. Therefore, somewhat controversially, a temporary moratorium on research that is purely focused on the passage of objective time (i.e., longitudinal research) may be needed until we fully understand how, in the words of the Coleridge quote above, individuals and collectives coinstantaneously perceive, interpret, and mentally travel across past, present, and future.

\section{CONCLUSION}

In this review, we demonstrated the importance of subjective time in organizations, synthesizing past work and creating a set of challenges for future research. Rather than viewing subjective time as a sidelined "other" time, we placed it front and center to demonstrate its importance for management research. Such contributions not only help to organize and direct research on subjective time and its intersection with management research 
domains, but also lay the groundwork for additional theorizing on the topic, particularly research on its intersection with objective time. It is oft lamented that there are no formal theories of time (Shipp \& Fried, 2014). However, any assumptions that such a theory cannot be developed stem from a mostly objective time view, which is undergirded by subjective time. Previously, there had not been enough studies of the elements of subjective time to lay the groundwork for a theory of time itself. However, given our work to establish the building blocks of such a theory (e.g., conceptualizations, mechanisms, and impact of subjective time), we are optimistic that a formal, "capital-T" theory of time is in the near future, with subjective time at its core. 


\section{REFERENCES}

Articles from our seminal review are denoted by ** and articles in our sample are denoted by *

**Adam, B. (1990). Time and Social Theory. Philadelphia, PA: Temple University Press.

*Adorisio, A. L. M. (2014). Organizational remembering as narrative: 'Storying' the past in banking, Organization, 21(4), 463-476.

Albert, S. (1977). Temporal comparison theory. Psychological Review, 84(6), 485-503.

*Alipour, K. K., Mohammed, S., \& Martinez, P. N. (2017). Incorporating temporality into implicit leadership and followership theories: Exploring inconsistencies between time-based expectations and actual behaviors. Leadership Quarterly, 28(2), 300-316.

Ancona, D. G., \& Chong, C. L. (1996). Entrainment: Pace, cycle, and rhythm in organizational behavior. In B. M. Staw and L. L. Cummings (Eds.), Research in Organizational Behavior, 18: 251-284.

**Ancona, D. G., Okhuysen, G. A., \& Perlow, L. A. (2001). Taking time to integrate temporal research. Academy of Management Review, 26(4), 512-529.

*Anteby, M., \& Molnar, V. (2012). Collective memory meets organizational identity: Remembering to forget in a firm's rhetorical history. Academy of Management Journal, 55(3), 515-540.

*Ashforth, B. E. (2012). The role of time in socialization. The Oxford Handbook of Socialization, Vol 1, 161-186.

Augustine, S. (AD 397-401). The Confessions.

**Avital, M. (2000). Dealing with time in social inquiry: A tension between method and lived experience. Organization Science, 11(6), 665-673.

*Bakker, R. M., Boroş, S., Kenis, P., \& Oerlemans, L. A. (2013). It's only temporary: time frame and the dynamics of creative project teams. British Journal of Management, 24(3), 383-397

*Ballard, D. I. (2008). Organizational temporality over time: Activity cycles as sources of entrainment. In R. A Roe, M. J. Waller, and S. R. Clegg (Eds.), Time in Organizational Research (pp. 204-219). New York: Routledge.

*Ballard, D. I., \& Gossett, L. M. (2007). Alternative times: Temporal perceptions, processes, and practices defining the nonstandard work relationship. Annals of the International Communication Association, 31(1), 274-320.

*Ballard, D. I., \& Seibold, D. R. (2003). Communicating and organizing in time: A mesolevel model of organizational temporality. Management Communication Quarterly, 16(3), 380-415.

*Ballard, D. I., \& Seibold, D. R. (2006). The experience of time at work: Relationship to communication load, job satisfaction, and interdepartmental communication. Communication Studies, 57(3), 317-340.

*Balogun, J., \& Johnson, G. (2005). From intended strategies to unintended outcomes: The impact of change recipient sensemaking. Organization Studies, 26(11), 1573-1601.

*Barge, J. K., \& Oliver, C. (2003). Working with appreciation in managerial practice. Academy of Management Review, 28(1), 124-142.

*Bartunek, J. M., \& Woodman, R. W. (2015). Beyond Lewin: Toward a temporal approximation of organization development and change. Annual Review of Organizational Psychology and Organizational Behavior, 2, 157-182).

*Baumeister, R. F., Vohs, K. D., Oettingen, G. (2016) Pragmatic prospection: How and why people think about the future. Review of General Psychology, 20(1), 3-16.

*Bean, C. J., \& Hamilton, F. E. (2006). Leader framing and follower sensemaking: Response to downsizing in the brave new workplace. Human Relations, 59(3), 321-349.

*Berg Johansen, C., \& De Cock, C. (2018). Ideologies of time: How elite corporate actors 
engage the future. Organization, 25(2), 186-204.

**Bergadaà, M. M. (1990). The role of time in the action of the consumer. Journal of Consumer Research, 17(3), 289-302.

**Bergmann, W. (1992). The problem of time in sociology: An overview of the literature on the state of theory and research on the sociology of time, 1900-82. Time \& Society, $1(1), 81-134$.

*Bligh, M. C., Kohles, J. C., \& Meindl, J. R. (2004). Charisma under crisis: Presidential leadership, rhetoric, and media responses before and after the September 11th terrorist attacks. Leadership Quarterly, 15(2), 211-239.

**Block, R. A. (1990). Cognitive Models of Psychological Time. New York: Lawrence Erlbaum.

*Blount, S., \& Janicik, G. A. (2001). When plans change: Examining how people evaluate timing changes in work organizations. Academy of Management Review, 26(4), 566585.

**Bluedorn, A. C. (2002). The Human Organization of Time: Temporal Realities and Experience. Stanford CA: Stanford University Press.

**Bluedorn, A. C., \& Denhardt, R. B. (1988). Time and organizations. Journal of Management, 14(2), 299-320.

*Bluedorn, A. C., \& Jaussi, K. S. (2008). Leaders, followers, and time. Leadership Quarterly, 19(6), 654-668.

*Bordia, P., Restubog, S. L. D., Jimmieson, N. L., \& Irmer, B. E. (2011). Haunted by the past: Effects of poor change management history on employee attitudes and turnover. Group \& Organization Management, 36(2), 191-222.

*Bowman, G. (2016). The practice of scenario planning: An analysis of inter-and intraorganizational strategizing. British Journal of Management, 27(1), 77-96.

*Brislin, R., \& Kim, E. (2003). Cultural diversity in people's understanding and uses of time. Applied Psychology: An International Review, 52(3), 363-382.

*Brown, A. D., \& Humphreys, M. (2002). Nostalgia and the narrativization of identity: A Turkish case study. British Journal of Management, 13(2), 141-159.

Brown, K. W., \& Ryan, R. M. (2003). The benefits of being present: Mindfulness and its role in psychological well-being. Journal of Personality and Social Psychology, 84(4), 822.

*Brown, A. D., Stacey, P., \& Nandhakumar, J. (2008). Making sense of sensemaking narratives. Human Relations, 61(8), 1035-1062.

*Buehler, R., \& Griffin, D. (1994). Change-of-meaning effects in conformity and dissent: Observing construal processes over time. Journal of Personality and Social Psychology, 67(6), 984-996.

**Butler, R. (1995). Time in organizations: Its experience, explanations and effects. Organization Studies, 16(6), 925-950.

*Carlsen, A. (2006). Organizational becoming as dialogic imagination of practice: The case of the indomitable Gauls. Organization Science, 17(1), 132-149.

Carton, A. M. (2018). "I'm not mopping the floors, I'm putting a man on the moon": How NASA leaders enhanced the meaningfulness of work by changing the meaning of work. Administrative Science Quarterly, 63(2), 323-369.

*Chen, J., \& Nadkarni, S. (2017). It's about time! CEOs' temporal dispositions, temporal leadership, and corporate entrepreneurship. Administrative Science Quarterly, 62(1), 31-66.

**Clark, P. A. (1985). A review of the theories of time and structure for organizational sociology. In S. B. Bacharach \& S. M. Mitchell (Eds.), Research in the Sociology of Organizations: 35-79. Greenwich, CT: JAI Press. 
*Clark, T., \& Greatbatch, D. (2011). Audience perceptions of charismatic and noncharismatic oratory: The case of management gurus. Leadership Quarterly, 22(1), 2232.

*Cojuharenco, I., Patient, D., \& Bashshur, M. R. (2011). Seeing the "forest" or the "trees" of organizational justice: Effects of temporal perspective on employee concerns about unfair treatment at work. Organizational Behavior and Human Decision Processes, 116(1), 17-31.

*Cole, M. S., Shipp, A. J., \& Taylor, S. G. (2016). Viewing the interpersonal mistreatment literature through a temporal lens. Organizational Psychology Review, 6(3), 273-302.

*Comi, A., \& Whyte, J. (2018). Future making and visual artefacts: an ethnographic study of a design project. Organization Studies, 39(8), 1055-1083.

Conte, J.M. (2007). Measuring temporal constructs across multiple levels of analysis. In F. Dansereau and F. J. Yammarino, (Eds.) Multi-Level Issues in Organizations and Time (Research in Multi-Level Issues, Vol. 6), Emerald Group Publishing Limited, Bingley, pp. 225-237.

*Costas, J., \& Grey, C. (2014). The temporality of power and the power of temporality: Imaginary future selves in professional service firms. Organization Studies, 35(6), 909-937.

*Crilly, D. (2017). Time and space in strategy discourse: Implications for intertemporal choice. Strategic Management Journal, 38(12), 2370-2389.

Cronin, M. A., Weingart, L. R., \& Todorova, G. (2011). Dynamics in groups: Are we there yet? Academy of Management Annals, 5(1), 571-612.

*Cunha, M. P. E. (2004a). Organizational time: a dialectical view. Organization, 11(2), 271296.

*Cunha, M. P. E. (2004b). Time traveling: Organizational foresight as temporal reflexivity. In H. Tsoukas and J. Shepherd (Eds.) Managing the Future: Foresight in the Knowledge Economy (pp. 133-149). Malden, MA: Blackwell.

*Cunha, M. P. E., \& Cunha, R. C. E. (2004). Changing a cultural grammar? The pressure towards the adoption of "Northern time" by Southern European managers. Journal of Managerial Psychology, 19(8), 795-808.

**Cunliffe, A. L., Luhman, J. T., \& Boje, D. M. (2004). Narrative temporality: Implications for organizational research. Organization Studies, 25(2), 261-286.

*Cutcher, L., Dale, K., \& Tyler, M. (2019). 'Remembering as Forgetting': Organizational commemoration as a politics of recognition. Organization Studies, 40(2), 267-290.

*Dahm, P. C., Kim, Y., Glomb, T. M., \& Harrison, S. (2019) Identity affirmation as threat? Time-bending sensemaking and the career and family identity patterns of early achievers. Academy of Management Journal, 62(4), 1194-1225.

*Dane, E. (2018). Where is my mind? Theorizing mind wandering and its performancerelated consequences in organizations. Academy of Management Review, 43(2), 179197.

*Dane, E., \& George, J. M. (2014). Unpacking affective forecasting and its ties to project work in organizations. Academy of Management Review, 39(2), 181-201.

*Das, T. K. (1987). Strategic planning and individual temporal orientation. Strategic Management Journal, 8(2), 203-209.

**Das, T. K. (1993). Time in management and organizational studies. Time \& Society, 2(2), 267-274.

*Das, T. K. (2004). Strategy and time: really recognizing the future. In H. Tsoukas and J. Shepherd (Eds.) Managing the Future: Foresight in the Knowledge Economy (pp. 5874). Malden, MA: Blackwell.

*Das, T. K., \& Teng, B. S. (2001). Strategic risk behaviour and its temporalities: between 
risk propensity and decision context. Journal of Management Studies, 38(4), 515-534.

*Dawson, P. (2014). Reflections: On time, temporality and change in organizations. Journal of Change Management, 14(3), 285-308.

*DeVoe, S. E., \& Pfeffer, J. (2007). Hourly payment and volunteering: The effect of organizational practices on decisions about time use. Academy of Management Journal, 50(4), 783-798.

*DeVoe, S. E., \& Pfeffer, J. (2011). Time is tight: How higher economic value of time increases feelings of time pressure. Journal of Applied Psychology, 96(4), 665.

**Doob, L. W. (1971) Patterning of Time. New Haven, CT: Yale University Press.

Dougherty, D. (1992). Interpretive barriers to successful product innovation in large firms. Organization Science, 3(2), 179-202.

*Dougherty, D., Bertels, H., Chung, K., Dunne, D. D., \& Kraemer, J. (2013). Whose time is it? Understanding clock-time pacing and event-time pacing in complex innovations. Management and Organization Review, 9(2), 233-264.

*Dunn, E. W., Brackett, M. A., Ashton-James, C., Schneiderman, E., \& Salovey, P. (2007). On emotionally intelligent time travel: Individual differences in affective forecasting ability. Personality and Social Psychology Bulletin, 33(1), 85-93.

Durkheim, E. (1915). The elementary forms of the religious life. George Allen and Unwin Limited.

*Eldor, L., Fried, Y., Westman, M., Levi, A. S., Shipp, A. J., \& Slowik, L. H. (2017). The experience of work stress and the context of time: Analyzing the role of subjective time. Organizational Psychology Review, 7(3), 227-249.

*Eury, J. L., Kreiner, G. E., Trevino, L. K., \& Gioia, D. A. (2018). The past is not dead: Legacy identification and alumni ambivalence in the wake of the Sandusky scandal at Penn State. Academy of Management Journal, 61(3), 826-856.

*Evans, J. A., Kunda, G., \& Barley, S. R. (2004). Beach time, bridge time, and billable hours: The temporal structure of technical contracting. Administrative Science Quarterly, 49(1), 1-38.

*Feldman, R. M., \& Feldman, S. P. (2006). What links the chain: An essay on organizational remembering as practice. Organization, 13(6), 861-887.

Feldman, M. S., \& Pentland, B. T. (2003). Reconceptualizing organizational routines as a source of flexibility and change. Administrative Science Quarterly, 48: 94-118.

Feldman, E., Reid, E. M., \& Mazmanian, M. (in press). Signs of our time: Time-use as dedication, performance, identity, and power in contemporary workplaces. Academy of Management Annals.

*Fine, G. A., \& Hallett, T. (2014). Group cultures and the everyday life of organizations: Interaction orders and meso-analysis. Organization Studies, 35(12), 1773-1792.

*Fisher, S. R., \& White, M. A. (2000). Downsizing in a learning organization: are there hidden costs? Academy of Management Review, 25(1), 244-251.

Foo, M. D., Uy, M. A., \& Baron, R. A. (2009). How do feelings influence effort? An empirical study of entrepreneurs' affect and venture effort. Journal of Applied Psychology, 94(4), 1086-1094.

*Forray, J. M., \& Woodilla, J. (2002). Temporal spans in talk: doing consistency to construct fair organization. Organization Studies, 23(6), 899-916.

**Fraisse, P. (1963). The Psychology of Time (J. Leith, Trans.). New York: Harper \& Row.

*Fried, Y., \& Slowik, L. H. (2004). Enriching goal-setting theory with time: An integrated approach. Academy of Management Review, 29(3), 404-422.

*Gabriel, Y. (1995). The unmanaged organization: Stories, fantasies and subjectivity. Organization Studies, 16(3), 477-501.

*Gamache, D. L., \& McNamara, G. (2019). Responding to bad press: How CEO temporal 
focus influences the sensitivity to negative media coverage of acquisitions. Academy of Management Journal, 62(3), 918-943.

*Garud, R., Gehman, J., \& Kumaraswamy, A. (2011). Complexity arrangements for sustained innovation: Lessons from 3M Corporation. Organization Studies, 32(6), 737-767.

**George, J. M., \& Jones, G. R. (2000). The role of time in theory and theory building. Journal of Management, 26(4), 657-684.

Gersick, C. J. (1994). Pacing strategic change: The case of a new venture. Academy of Management Journal, 37(1), 9-45.

Gevers, J. M., Rutte, C. G., \& Van Eerde, W. (2006). Meeting deadlines in work groups: Implicit and explicit mechanisms. Applied Psychology, 55(1), 52-72.

* Gherardi, S., \& Strati, A. (1988). The temporal dimension in organizational studies. Organization Studies, 9(2), 149-164.

*Gibson, C. B., Waller, M. J., Carpenter, M. A., \& Conte, J. M. (2007). Antecedents, consequences, and moderators of time perspective heterogeneity for knowledge management in MNO teams. Journal of Organizational Behavior, 28(8), 1005-1034.

Gioia, D. A., Schultz, M., \& Corley, K. G. (2000). Organizational identity, image and adaptive instability. Academy of Management Review, 25: 63-81.

*Good, D. J., Lyddy, C. J., Glomb, T. M., Bono, J. E., Brown, K. W., Duffy, M. K., Baer, R.A., Brewer, J.A., \& Lazar, S. W. (2016). Contemplating mindfulness at work: An integrative review. Journal of Management, 42(1), 114-142.

*Granqvist, N., \& Gustafsson, R. (2016). Temporal institutional work. Academy of Management Journal, 59(3), 1009-1035.

Grant, A. M. (2012). Leading with meaning: Beneficiary contact, prosocial impact, and the performance effects of transformational leadership. Academy of Management Journal, $55(2), 458-476$.

*Gray, B., Bougon, M. G., \& Donnellon, A. (1985). Organizations as constructions and destructions of meaning. Journal of Management, 11(2), 83-98.

*Gray, B., Purdy, J. M., \& Ansari, S. (2015). From interactions to institutions: Microprocesses of framing and mechanisms for the structuring of institutional fields. Academy of Management Review, 40(1), 115-143.

*Green Jr, S. E., \& Li, Y. (2011). Rhetorical institutionalism: Language, agency, and structure in institutional theory since Alvesson 1993. Journal of Management Studies, 48(7), 1662-1697.

*Halbesleben, J. R., Novicevic, M. M., Harvey, M. G., \& Buckley, M. R. (2003). Awareness of temporal complexity in leadership of creativity and innovation: A competencybased model. Leadership Quarterly, 14(4-5), 433-454.

*Haley, U. C., \& Boje, D. M. (2014). Storytelling the internationalization of the multinational enterprise. Journal of International Business Studies, 45(9), 1115-1132.

*Harris, S. G. (1994). Organizational culture and individual sensemaking: A schema-based perspective. Organization Science, 5(3), 309-32

**Hassard, J. (1991). Aspects of time in organizations. Human Relations, 44, 105-136.

*Hatch, M. J. (1993). The dynamics of organizational culture. Academy of Management Review, 18(4), 657-693.

*Hatch, M. J. (2000). The cultural dynamics of organizing and change. In N. Ashkanasy, C. Wilderom and M. Peterson (Eds.) Handbook of Organizational Culture and Climate (pp. 245-260). Thousand Oaks, CA: Sage.

*Hatch, M. J., \& Schultz, M. (2017). Toward a theory of using history authentically: Historicizing in the Carlsberg Group. Administrative Science Quarterly, 62(4), 657697. 
Heintzelman, S. J., Trent, J., \& King, L. A. (2013). Encounters with objective coherence and the experience of meaning in life. Psychological Science, 24(6), 991-998.

*Hellström, T., \& Hellström, C. (2002). Time and innovation in independent technological ventures. Human Relations, 55(4), 407-426.

Hernadi, P. (1992). Objective, subjective, intersubjective times: Guest editor's introduction. Time and Society, 1, 147-158.

Hernes, T. (2017). Process as the becoming of temporal trajectory. In Sage Handbook of Process Organization Studies (pp. 601-607). SAGE Publications.

*Hershfield, H. E., Cohen, T. R., \& Thompson, L. (2012). Short horizons and tempting situations: Lack of continuity to our future selves leads to unethical decision making and behavior. Organizational Behavior and Human Decision Processes, 117(2), 298310.

*Hobson, N. M., Schroeder, J., Risen, J. L., Xygalatas, D., \& Inzlicht, M. (2018). The psychology of rituals: An integrative review and process-based framework. Personality and Social Psychology Review, 22(3), 260-284.

*Höllerer, M. A., Jancsary, D., \& Grafström, M. (2018). 'A picture is worth a thousand words': Multimodal sensemaking of the Global Financial Crisis. Organization Studies, 39(5) 617-644.

Holman, E. A., Silver, R. C., Mogle, J. A., \& Scott, S. B. (2016). Adversity, time, and wellbeing: A longitudinal analysis of time perspective in adulthood. Psychology and Aging, 31(6), 640-651.

*Hopp, C., \& Greene, F. J. (2018). In pursuit of time: Business plan sequencing, duration and intraentrainment effects on new venture viability. Journal of Management Studies, 55(2), 320-351.

*Howard-Grenville, J. A. (2005). The persistence of flexible organizational routines: The role of agency and organizational context. Organization Science, 16(6), 618-636.

**Huy, Q. (2001). Time, temporal capability, and planned change. Academy of Management Review, 26(4), 601-623.

*Ibarra, H. (1999). Provisional selves: Experimenting with image and identity in professional adaptation. Administrative Science Quarterly, 44(4), 764-791.

*Ibarra, H., \& Barbulescu, R. (2010). Identity as narrative: Prevalence, effectiveness, and consequences of narrative identity work in macro work role transitions. Academy of Management Review, 35(1), 135-154.

*Islam, G. (2012). Recognition, reification, and practices of forgetting: Ethical implications of human resource management. Journal of Business Ethics, 111(1), 37-48.

*Jansen, K. J. (2004). From persistence to pursuit: A longitudinal examination of momentum during the early stages of strategic change. Organization Science, 15(3), 276-294.

*Jansen, K. J., \& Shipp, A. J. (2019). Fitting as a temporal sensemaking process: Shifting trajectories and stable themes. Human Relations, 72(7), 1154-1186.

**Jaques, E. (1982). The Form of Time. New York: Crane Russak \& Company.

*Jordan, S. L., Ferris, G. R., \& Lamont, B. T. (2019). A framework for understanding the effects of past experiences on justice expectations and perceptions of human resource inclusion practices. Human Resource Management Review, 29(3), 386-399.

*Kaplan, S., \& Orlikowski, W. J. (2013). Temporal work in strategy making. Organization Science, 24: 965-995.

Karau, S. J., \& Kelly, J. R. (1992). The effects of time scarcity and time abundance on group performance quality and interaction process. Journal of Experimental Social Psychology, 28(6): 542-571.

*Kim, A., Bansal, P., \& Haugh, H. (2019). No time like the present: How a present time perspective can foster sustainable development. Academy of Management Journal, 
62(2), 607-634.

*Kimberly, J. R., \& Bouchikhi, H. (1995). The dynamics of organizational development and change: How the past shapes the present and constrains the future. Organization Science, 6(1), 9-18.

King, L. A., Heintzelman, S. J., \& Ward, S. J. (2016). Beyond the search for meaning: A contemporary science of the experience of meaning in life. Current Directions in Psychological Science, 25(4), 211-216.

*Kooij, D. T., Kanfer, R., Betts, M., \& Rudolph, C. W. (2018). Future time perspective: A systematic review and meta-analysis. Journal of Applied Psychology, 103(8), 867893.

*Kreiner, G. E., Hollensbe, E., Sheep, M. L., Smith, B. R., \& Kataria, N. (2015). Elasticity and the dialectic tensions of organizational identity: How can we hold together while we are pulling apart? Academy of Management Journal, 58(4), 981-1011.

*Kruglanski, A. W., Pierro, A., \& Higgins, E. T. (2016). Experience of time by people on the go: A theory of the locomotion-temporality interface. Personality and Social Psychology Review, 20(2), 100-117.

*Kunisch, S., Bartunek, J. M., Mueller, J., \& Huy, Q. N. (2017). Time in strategic change research. Academy of Management Annals, 11(2), 1005-1064.

*Ladge, J. J., Clair, J. A., \& Greenberg, D. (2012). Cross-domain identity transition during liminal periods: Constructing multiple selves as professional and mother during pregnancy. Academy of Management Journal, 55(6), 1449-1471.

Landy, F. J., Rastegary, H., Thayer, J., \& Colvin, C. (1991). Time urgency: The construct and its measurement. Journal of Applied Psychology, 76(5), 644.

Langley, A. 1999. Strategies for theorizing from process data. Academy of Management Review, 24: 691- 710.

**Lee, H., \& Liebenau, J. (1999). Time in organizational studies: Towards a new research direction. Organization Studies, 20(6), 1035-1058.

*Levine, R. (2005). A geography of busyness. Social Research, 72, 355-370.

**Lewin, K. (1943). Defining the 'field at a given time.' Psychological Review, 50(3), 292310.

**Lewis, J. D., \& Weigert, A. J. (1981). The structures and meanings of social time. Social Forces, 60(2), 432-462.

*Lin, Y., Shi, W., Prescott, J. E., \& Yang, H. (2019). In the eye of the beholder: Top managers' long-term orientation, industry context, and decision-making processes. Journal of Management, 45(8), 3114-3145.

*Lord, R. G., Dinh, J. E., \& Hoffman, E. L. (2015). A quantum approach to time and organizational change. Academy of Management Review, 40(2), 263-290.

Luciano, M. M., Mathieu, J. E., Park, S., \& Tannenbaum, S. I. (2018). A fitting approach to construct and measurement alignment: the role of big data in advancing dynamic theories. Organizational Research Methods, 21(3), 592-632.

Lumpkin, G. T., \& Brigham, K. H. (2011). Long-term orientation and intertemporal choice in family firms. Entrepreneurship Theory and Practice, 35(6), 1149-1169.

*Maclean, M., Harvey, C., Sillince, J. A. A., \& \& Golant, B. D. (2014) 'Living up to the Past? Ideological Sensemaking in Organisational Transition'. Organization, 21(4), 543-67.

Maitlis, S., \& Christianson, M. (2014) Sensemaking in organizations: Taking stock and moving forward. The Academy of Management Annals, 8(1), 57-125.

Markus, H., \& Nurius, P. (1986). Possible selves. American Psychologist, 41(9), 954-969.

*McGivern, G., Dopson, S., Ferlie, E., Fischer, M., Fitzgerald, L., Ledger, J., \& Bennett, C. (2018). The silent politics of temporal work: A case study of a management 
consultancy project to redesign public health care. Organization Studies, 39(8), 10071030.

**McGrath, J. E., \& Kelly, J. R. (1986). Time and Human Interaction: Toward a Social Psychology of Time. New York: Guilford Press.

**McGrath, J. E., \& Rotchford, N. L. (1983). Time and behavior in organizations. Research in Organizational Behavior, 5, 57-101.

*Methot, J. R., Lepak, D., Shipp, A. J., \& Boswell, W. R. (2017). Good citizen interrupted: Calibrating a temporal theory of citizenship behavior. Academy of Management Review, 42(1), 10-31.

*Miettinen, R., \& Virkkunen, J. (2005). Epistemic objects, artefacts and organizational change. Organization, 12(3), 437-456.

**Mitchell, T. R., \& James, L. R. (2001). Building better theory: Time and the specification of when things happen. Academy of Management Review, 26(4), 530-547.

*Mohammed, S., \& Harrison, D. A. (2013). The clocks that time us are not the same: A theory of temporal diversity, task characteristics, and performance in teams. Organizational Behavior and Human Decision Processes, 122(2), 244-256.

*Mohammed, S., \& Nadkarni, S. (2011). Temporal diversity and team performance: The moderating role of team temporal leadership. Academy of Management Journal, 54(3), 489-508.

*Mohammed, S., \& Nadkarni, S. (2014). Are we all on the same temporal page? The moderating effects of temporal team cognition on the polychronicity diversity-team performance relationship. Journal of Applied Psychology, 99(3), 404-422.

*Mohammed, S., Hamilton, K., Tesler, R., Mancuso, V., \& McNeese, M. (2015). Time for temporal team mental models: Expanding beyond "what" and "how" to incorporate "when". European Journal of Work and Organizational Psychology, 24(5), 693-709.

Morgeson, F. P., Mitchell, T. R., \& Liu, D. (2015). Event system theory: An event-oriented approach to the organizational sciences. Academy of Management Review, 40(4), 515537.

**Mosakowski, E., \& Earley, P. C. (2000). A selective review of time assumptions in strategy research. Academy of Management Review, 25(4), 796-812.

Muldoon, M. S. (2006). Tricks of Time: Bergson, Merleau-Ponty and Ricoeur in Search of Time, Self, and Meaning. Duquesne University Press: Pittsburgh.

Murray H (1938) Explorations in Personality: A Clinical and Experimental Study of Fifty Men of College Age. New York: Oxford University Press.

*Nadkarni, S., \& Chen, J. (2014). Bridging yesterday, today, and tomorrow: CEO temporal focus, environmental dynamism, and rate of new product introduction. Academy of Management Journal, 57(6), 1810-1833.

*Nadkarni, S., Chen, T., \& Chen, J. (2016). The clock is ticking! Executive temporal depth, industry velocity, and competitive aggressiveness. Strategic Management Journal, 37(6), 1132-1153.

Nadkarni, S., Pan, L., \& Chen, T. (2019). Only timeline will tell: Temporal framing of competitive announcements and rivals' responses. Academy of Management Journal, 62(1), 117-143.

New York Times (2020, March 30). The human stories of the coronavirus pandemic. Retrieved from: https://www.nytimes.com/2020/03/30/us/coronavirus-world-newsupdates.html

**Orlikowski, W. J., \& Yates, J. (2002). It's about time: Temporal structuring in organizations. Organization Science, 13(6), 684-700.

*Ortiz-de-Mandojana, N., Bansal, P., \& Aragón-Correa, J. A. (2019). Older and wiser: How CEOs' time perspective influences long-term investments in environmentally 
responsible technologies. British Journal of Management, 30(1), 134-150.

**Perlow, L. A. (1999). The time famine: Toward a sociology of work time. Administrative Science Quarterly, 44(1), 57-81.

Pitariu, A. H., \& Ployhart, R. E. (2010). Explaining change: Theorizing and testing dynamic mediated longitudinal relationships. Journal of Management, 36(2), 405-429.

Ployhart, R. E., \& Vandenberg, R. J. (2010). Longitudinal research: The theory, design, and analysis of change. Journal of Management, 36(1), 94-120.

*Rämö, H. (2004). Moments of trust: Temporal and spatial factors of trust in organizations. Journal of Managerial Psychology, 19(8), 760-775.

*Ranson, S., Hinings, B., \& Greenwood, R. (1980). The structuring of organizational structures. Administrative Science Quarterly, 1-17.

*Ravasi, D., \& Schultz, M. (2006). Responding to organizational identity threats: Exploring the role of organizational culture. Academy of Management Journal, 49(3), 433-458.

*Reilly, G., Souder, D., \& Ranucci, R. (2016). Time horizon of investments in the resource allocation process: Review and framework for next steps. Journal of Management, 42(5), 1169-1194.

*Reinecke, J., \& Ansari, S. (2015). When times collide: Temporal brokerage at the intersection of markets and developments. Academy of Management Journal, 58(2), 618-648.

*Reinsch Jr, N. L., Turner, J. W., \& Tinsley, C. H. (2008). Multicommunicating: A practice whose time has come? Academy of Management Review, 33(2), 391-403.

Rosso, B. D., Dekas, K. H., \& Wrzesniewski, A. (2010). On the meaning of work: A theoretical integration and review. Research in Organizational Behavior, 30, 91-127.

*Rowlinson, M., Booth, C., Clark, P., Delahaye, A., \& Procter, S. (2010). Social remembering and organizational memory. Organization Studies, 31(1), 69-87.

*Rudolph, C. W., Kooij, D. T., Rauvola, R. S., \& Zacher, H. (2018). Occupational future time perspective: A meta-analysis of antecedents and outcomes. Journal of Organizational Behavior, 39(2), 229-248.

Rush, J., \& Grouzet, F. M. (2012). It is about time: Daily relationships between temporal perspective and well-being. The Journal of Positive Psychology, 7(5), 427-442.

**Russell, B. (1915). On the experience of time. The Monist, 25(2), 212-233.

*Saunders, C., Van Slyke, C., \& Vogel, D. R. (2004). My time or yours? Managing time visions in global virtual teams. Academy of Management Perspectives, 18(1), 19-37.

Schoemaker, P. J. (1993). Multiple scenario development: Its conceptual and behavioral foundation. Strategic Management Journal, 14(3), 193-213.

*Schrempf-Stirling, J., Palazzo, G., \& Phillips, R. A. (2016). Historic corporate social responsibility. Academy of Management Review, 41(4), 700-719.

*Schriber, J. B., \& Gutek, B. A. (1987). Some time dimensions of work: Measurement of an underlying aspect of organization culture. Journal of Applied Psychology, 72(4), 642650.

*Schultz, M., \& Hernes, T. (2013). A temporal perspective on organizational identity. Organization Science, 24(1), 1-21.

Seixas, P. C. (2004). Theorizing historical consciousness. Toronto: University of Toronto Press.

*Shamir, B., Arthur, M. B., \& House, R. J. (1994). The rhetoric of charismatic leadership: A theoretical extension, a case study, and implications for research. Leadership Quarterly, 5(1), 25-42.

Shapiro, D. L., \& Kirkman, B. L. (2001). Anticipatory injustice: The consequences of expecting injustice in the workplace. Advances in Organizational Justice, 32(5), 152178. 
Shipp, A. J., \& Aeon, B. (2019). Temporal focus: Thinking about the past, present, and future. Current Opinion in Psychology, 26, 37-43.

**Shipp, A. J., \& Cole, M. S. (2015). Time in individual-level organizational studies: What is it, how is it used, and why isn't it exploited more often? Annual Review of Organizational Psychology and Organizational Behavior, 2(1), 237-260.

Shipp, A. J., \& Fried, Y. (2014). Time research in management: Using temporal ambassadors to translate ideas into reality. In A. J. Shipp \& Y. Fried (Eds.), Time and Work: How Time Impacts Individuals (Vol. 1, p. 1-10). East Sussex, UK: Psychology Press.

*Shipp, A. J., \& Jansen, K. J. (2011). Reinterpreting time in fit theory: Crafting and recrafting narratives of fit in medias res. Academy of Management Review, 36(1), 76101.

*Shipp, A. J., Edwards, J. R., \& Lambert, L. S. (2009). Conceptualization and measurement of temporal focus: The subjective experience of the past, present, and future. Organizational Behavior and Human Decision Processes, 110(1), 1-22.

*Slawinski, N., \& Bansal, P. (2012). A matter of time: The temporal perspectives of organizational responses to climate change. Organization Studies, 33(11), 1537-1563.

*Slawinski, N., \& Bansal, P. (2017). The paradoxes of time in organizations. In W. K. Smith, P. Jarzabkowski, M. W. Lewis, \& A. Langley (Eds.), The Oxford Handbook of Organizational Paradox (p. 373-392). Oxford University Press.

Smallwood, J., \& Schooler, J. W. (2006). The restless mind. Psychological Bulletin, 132(6), 946-958.

**Sorokin, P. A., \& Merton, R. K. (1937). Social time: A methodological and functional analysis. American Journal of Sociology, 42(5), 615-629.

Standifer, R., \& Bluedorn, A. (2006). Alliance management teams and entrainment: Sharing temporal mental models. Human Relations, 59(7), 903-927.

*Staudenmayer, N., Tyre, M., \& Perlow, L. (2002). Time to change: Temporal shifts as enablers of organizational change. Organization Science, 13(5), 583-597.

*Strauss, K., Griffin, M. A., \& Parker, S. K. (2012). Future work selves: How salient hopedfor identities motivate proactive career behaviors. Journal of Applied Psychology, 97(3), 580.

Strathman, A., Gleicher, F., Boninger, D. S., \& Edwards, C. S. (1994). The consideration of future consequences: weighing immediate and distant outcomes of behavior. Journal of Personality and Social Psychology, 66(4), 742-752.

*Strobel, M., Tumasjan, A., Spörrle, M., \& Welpe, I. M. (2013). The future starts today, not tomorrow: How future focus promotes organizational citizenship behaviors. Human Relations, 66(6), 829-856.

*Suddaby, R., \& Foster, W. M. (2017). History and Organizational Change. Journal of Management, 43(1), 19-38.

Suddaby, R., Foster, W., \& Quinn-Trank, C. 2010. Rhetorical history as a source of competitive advantage. In J. A. C. Baum \& J. Lampel (Eds.), Advances in Strategic Management: The Globalization of Strategy Research, Vol. 27: 147-173. Bingley, U.K.: Emerald Group.

Suddendorf, T., \& Corballis, M. C. (2007). The evolution of foresight: What is mental time travel, and is it unique to humans? Behavioral and Brain Sciences, 30(3), 299-313.

Tang, S., Richter, A., \& Nadkarni, S. (2020). Subjective time in organizations: Conceptual clarification, integration, and implications for future research. Journal of Organizational Behavior, 41(2), 210-234.

*Thompson, M. P., \& Walsham, G. (2004). Placing knowledge management in context. Journal of Management Studies, 41(5), 725-747.

Trope, Y., \& Liberman, N. (2003). Temporal construal. Psychological Review, 110(3), 403- 
421.

*Van de Ven, A. H., \& Poole, M. S. (2005). Alternative approaches for studying organizational change. Organization Studies, 26(9), 1377-1404.

*Vesa, M., \& Franck, H. (2013). Bringing strategy to time, studying strategy as experiential vectors. Scandinavian Journal of Management, 29(1), 23-34.

*Waller, M. J., Conte, J. M., Gibson, C. B., \& Carpenter, M. A. (2001). The effect of individual perceptions of deadlines on team performance. Academy of Management Review, 26(4), 586-600.

*Walsh, J. P., \& Ungson, G. R. (1991). Organizational memory. Academy of Management Review, 16(1), 57-91.

Weick, K. E. (1995). Sensemaking in Organizations (Vol. 3). Sage.

Weisbord, M. R. (1988). Towards a new practice theory of OD: Notes on snapshooting and moviemaking. In W. Pasmore, and R. W. Woodman (Eds.), Research in Organizational Change and Development (Vol. 2, pp. 59-96). Greenwich, CT: JAI Press.

Wilson, T. D., \& Gilbert, D. T. (2003). Affective forecasting. In M. P. Zanna (Ed.), Advances in Experimental Social Psychology, Vol. 35 (p. 345-411). Elsevier Academic Press.

*Wittman, S. (2019). Lingering identities. Academy of Management Review, 44(4), 724-745.

*Wolfram Cox, J. R. (1997). Manufacturing the past: Loss and absence in organizational change. Organization Studies, 18(4), 623-654.

Ybema, S. 2004. Managerial postalgia: Projecting a golden future. Journal of Managerial Psychology 19(8): 825-841.

*Ybema, S. (2010). Talk of change: Temporal contrasts and collective identities. Organization Studies, 31(4), 481-503.

*Ybema, S. (2014). The invention of transitions: History as a symbolic site for discursive struggles over organisational change. Organization, 21(4), 495-513.

Zacher, H., \& Frese, M. (2009). Remaining time and opportunities at work: relationships between age, work characteristics, and occupational future time perspective. Psychology and Aging, 24(2), 487-493.

**Zerubavel, E. (1981). Hidden Rhythms: Schedules and Calendars in Social Life. Chicago: University of Chicago Press.

**Zerubavel, E. (1985). The Seven-day Circle: The History and Meaning of the Week. New York: Free Press.

*Zhang, W., Wang, H., \& Pearce, C. L. (2014). Consideration for future consequences as an antecedent of transformational leadership behavior: The moderating effects of perceived dynamic work environment. Leadership Quarterly, 25(2), 329-343.

Zimbardo, P. G., \& Boyd, J. N. (1999). Putting time in perspective: A valid, reliable individualdifferences metric. Journal of Personality and Social Psychology, 77(6), 1271-1288. 


\section{Author Biographies}

Abbie J. Shipp (a.shipp@tcu.edu) is a professor of management at Texas Christian University. She earned her Ph.D. in organizational behavior from the University of North Carolina. Her research predominantly focuses on the subjective and psychological experience of time including trajectories of work experiences, temporal focus, experiencing change, and person-environment fit over time.

Karen J. Jansen (karen.jansen@henley.ac.uk) is a Professor in Leadership and Change at Henley Business School. Her research broadly focuses on temporal and dynamic aspects of leading change, including shifting person-environment fit over time, the impact of significant events, and momentum fluctuations during change processes. She obtained her Ph.D. in organizational change at Texas A\&M University after 9 years experiencing change at IBM. 
TABLE 1

The History and Dimensions of Subjective Time in Seminal Time Articles

\section{INTERSUBJECTIVE TIME}

\begin{tabular}{lc}
\cline { 2 - 2 } Heritage & Sociology or Organizational Theory \\
\cline { 2 - 3 } Actor & Collective
\end{tabular}

Dimensions

Exemplar

Definitions

Citations (some reflect more than one dimension)

\section{Additional \\ Unique Terms}

\begin{tabular}{|c|c|}
\hline Socially Constructed Time & Event Time \\
\hline $\begin{array}{l}\text { "socially constructed through human } \\
\text { action... a product of the norms, } \\
\text { beliefs, and customs of individuals } \\
\text { and groups... co constructed } \\
\text { conceptualization of time...neither } \\
\text { fixed nor invariant. Time here is } \\
\text { seen as relative, contextual, organic, } \\
\text { and socially constructed." } \\
\text { (Orlikowski \& Yates, 2002, pp. 684- } \\
685 \text { ) }\end{array}$ & $\begin{array}{l}\text { "...event-based or cyclical work } \\
\text { processes may establish temporal } \\
\text { rhythms inconsistent with the } \\
\text { objective notion of time..." } \\
\text { (Bluedorn \& Denhardt, 1988, p. } \\
\text { 304) }\end{array}$ \\
\hline
\end{tabular}

Adam (1990); Ancona, Okhuysen, \& Perlow (2001); Bergmann (1992); Bluedorn (2002); Butler (1995); Cunliffe, Luhman, \& Boje, (2004); Fraisse (1963); George \& Jones (2000); Hassard (1991); Huy (2001); Lee \& Liebenau (1999); Mosakowski \& Earley (2000); Orlikowski \& Yates (2002); Perlow (1999); Sorokin \& Merton (1937); Zerubavel (1985)

Vital time (Avital, 2000); epochal time (Bluedorn, 2002); shared time (Lee \& Liebenau, 1999); interaction time and institutional time (Lewis \& Weigert, 1981); relative, organic, contextual time (Orlikowski \& Yates, 2002); temporal order (Zerubavel, 1981)
(1988), Butler (199

Weigert (1981); Mosakowski \&

Earley (2000); Orlikowski \& Yates (2002); Perlow (1999)

\section{INTRASUBJECTIVE TIME}

\begin{tabular}{|c|c|}
\hline \multicolumn{2}{|c|}{ Psychology } \\
\hline \multicolumn{2}{|c|}{ Individual } \\
\hline Psychological Time & Duration of Time \\
\hline $\begin{array}{l}\text { "...we speak of 'time perspective' } \\
\text { which includes the psychological } \\
\text { past and psychological future on the } \\
\text { reality-level... It is important to } \\
\text { realize that the psychological past } \\
\text { and the psychological future are } \\
\text { simultaneous parts of the } \\
\text { psychological field existing at a } \\
\text { given time } t . " \text { (Lewin, 1943, p. 303) }\end{array}$ & $\begin{array}{l}\text { "The awareness that an activity has } \\
\text { ended, is being experienced... or can } \\
\text { be anticipated is as good an } \\
\text { operational definition of the } \\
\text { psychological present as we can } \\
\text { demand...Such awareness...is } \\
\text { equivalent to temporal judgment } \\
\text { concerning either the duration of an } \\
\text { interval or its temporal relation to } \\
\text { other intervals (succession)" (Doob, } \\
\text { 1971, p. 8) }\end{array}$ \\
\hline
\end{tabular}

Block (1990); Butler (1995); Das (1993); Doob (1971); George \& Jones (2000); Lewin (1943);

Ancona et al. (2001); Block (1990); Cunliffe et al. (2004); Doob (1971); McGrath \& Rotchford (1983)

Cole (2015)

Personal time (Bergadaa, 1990); temporal pressure (Fraisse, 1963); inner time (Huy, 2001); kairos (Jaques, 1982); self time (Lewis \& Weigert, 1981); epochal time (McGrath \& Kelly, 1986); mental time (Russell, 1915) 
TABLE 2

Three Actions Underlying Subjective Time Conceptualizations

Subjective time: The experience of the past, present, and future, which occurs as individuals (intrasubjectively) and collectives (intersubjectively) mentally travel through, perceive, and interpret time.

\begin{tabular}{lll}
\hline \multicolumn{1}{c}{ Conceptual Actions } & \multicolumn{1}{c}{ Intersubjective Concepts } & \multicolumn{1}{c}{ Intrasubjective Concepts } \\
\hline Traveling Through Time & \multicolumn{1}{c}{$\mathbf{5 6 \%}$} & $\mathbf{4 4 \%}$ \\
$\begin{array}{l}\text { Individual or collective mental } \\
\text { travel through the past, present and } \\
\text { future }\end{array}$ & $\begin{array}{l}\text { Distal goals, historical narrative, } \\
\text { historicizing, imagination, long present, } \\
\text { nostalgia, organizational forgetting and } \\
\text { remembering, organizational memory, } \\
\text { rhetorical history }\end{array}$ & $\begin{array}{l}\text { Consideration of future consequences, } \\
\text { foresight, future selves, mind wandering } \\
\text { pragmatic prospection, temporal focus, } \\
\text { temporal framing }\end{array}$ \\
$\begin{array}{l}\text { Perceiving Time } \\
\begin{array}{l}\text { Individual or collective construal } \\
\text { and communication of time's } \\
\text { structure }\end{array}\end{array}$ & $\begin{array}{l}\text { Coordination, cycles, milestones, } \\
\text { organizational routines, presentism, time } \\
\text { structures, temporal team leadership }\end{array}$ & $\begin{array}{l}\text { Adjustment, deadline perceptions, flow of } \\
\text { time, mindfulness, pacing style, } \\
\text { polychronicity, psychological present, risk } \\
\text { horizons, temporal depth, temporal mental } \\
\text { models, time horizon, time urgency }\end{array}$
\end{tabular}

\section{Interpreting Time}

Individual or collective interpretation of time in terms of meaning, duration, quality, or importance

$67 \%$

$33 \%$

Connected time, constructing and reconstructing meaning, cultural dynamics, interpreting change, momentum, sensemaking, scenario planning, strategy making, temporal institutional work, tenseless time ("now moments"), value of time

\begin{abstract}
Anticipatory justice, evaluating timing changes, legacy identification, prevailing temporal agenda, temporal shifts, the right moment, time scarcity, time visions $\square$
\end{abstract}

Note: Percentages reflect balance of intersubjective versus intrasubjective articles within each category. 
TABLE 3

Subjective Time Mechanisms

\begin{tabular}{|c|c|c|c|c|}
\hline Function & Cluster & Terms & Exemplars in Our Sample & $\begin{array}{c}\text { \% of } \\
\text { Sample }\end{array}$ \\
\hline \multirow{3}{*}{$\begin{array}{l}\text { ATTENDING } \\
\text { The means by which individuals } \\
\text { and collectives selectively direct } \\
\text { attention to the past, present, or } \\
\text { future to assess and inform } \\
\text { present experiences }\end{array}$} & $\begin{array}{c}\text { Focus of Attention } \\
\text { Directing cognitive attention to a } \\
\text { particular time period to increase or filter } \\
\text { information }\end{array}$ & $\begin{array}{l}\text { Focus of attention, perceptual filtering, } \\
\text { strategic forgetting and remembering, } \\
\text { broader consideration of information, cross- } \\
\text { fertilization }\end{array}$ & $\begin{array}{l}\text { "We predicted and found that [this construct] was an important predictor of } \\
\text { what information people attend to and how they perceive this } \\
\text { information..." (Shipp et al., 2009, p. 16) }\end{array}$ & $23 \%$ \\
\hline & $\begin{array}{l}\text { Temporal Comparison } \\
\text { Evaluating the present by comparison } \\
\text { with the past and/or future }\end{array}$ & $\begin{array}{l}\text { Temporal comparison, reference point, } \\
\text { reinterpretation of past experiences, } \\
\text { collective reflection, future aspiration level }\end{array}$ & $\begin{array}{l}\text { "[this construct]...provides a way to compare past with present, past with } \\
\text { future, and present with future." (Eury et al., 2018, pp. 835-836) }\end{array}$ & $23 \%$ \\
\hline & $\begin{array}{l}\text { Temporal Influence } \\
\text { Direct influence of past and/or future } \\
\text { experiences on current affective } \\
\text { reactions }\end{array}$ & $\begin{array}{l}\text { Temporal influence of the past or future, } \\
\text { nostalgia, postalgia, rumination, regret, } \\
\text { worry, hope, anxiety }\end{array}$ & $\begin{array}{l}\text { "...the perceived past and future...can lead to negative emotions (e.g., regret } \\
\text { about past experiences, anxiety about anticipated futures)." (Good et al., } \\
\text { 2016, p. 120) }\end{array}$ & $14 \%$ \\
\hline \multirow[t]{2}{*}{$\begin{array}{l}\text { Associated action(s): Primarily } \\
\text { time traveling. }\end{array}$} & $\begin{array}{c}\text { Learning } \\
\text { Analyzing past experiences for lessons }\end{array}$ & $\begin{array}{l}\text { Learning, adaptation, overgeneralization } \\
\text { bias }\end{array}$ & $\begin{array}{l}\text { "...learning is a reflective process, played out by members at all levels of the } \\
\text { organization that involves the collection of information from both the } \\
\text { external and internal environments." (Fisher \& White, 2000, p. 245) }\end{array}$ & $8 \%$ \\
\hline & $\begin{array}{l}\text { Accumulation } \\
\text { Periods of time in which past } \\
\text { experiences are perceived to build before } \\
\text { reaching a threshold }\end{array}$ & $\begin{array}{l}\text { Accumulation, amplification, thresholds, } \\
\text { turning points }\end{array}$ & $\begin{array}{l}\text { "...incremental changes in the narrative may accumulate for some time } \\
\text { before individuals substantially recraft their narrative...to better reflect a } \\
\text { temporal evolution in motives or to reestablish thematic coherence." (Shipp } \\
\text { \& Jansen, 2011, p. 84) }\end{array}$ & $3 \%$ \\
\hline
\end{tabular}




\begin{tabular}{|c|c|c|c|c|}
\hline Function & Cluster & Terms & Exemplars in Our Sample & $\begin{array}{c}\% \text { of } \\
\text { Sample }\end{array}$ \\
\hline \multirow{2}{*}{$\begin{array}{l}\text { PREPARING } \\
\text { The means by which individuals } \\
\text { and collectives think about, } \\
\text { plan for, and act toward future } \\
\text { expectations in the present }\end{array}$} & $\begin{array}{l}\text { Projection } \\
\text { Considering future projections to inform } \\
\text { present actions }\end{array}$ & $\begin{array}{l}\text { Projection, planning, prospection, future- } \\
\text { oriented imagination, envisioning, } \\
\text { foreseeing, forecasting, visioning, goal } \\
\text { pursuit, motivation, self-regulation }\end{array}$ & $\begin{array}{l}\text { "...[this construct] affects the goals that individuals set for themselves, the } \\
\text { consequences that individuals anticipate for various courses of action, and } \\
\text { the choices and planning processes that individuals use to achieve desired } \\
\text { outcomes; thinking about the future allows people to motivate themselves } \\
\text { and guide their actions in anticipation of future events..." (Kooij et al., } \\
\text { 2018, p. 870) }\end{array}$ & $26 \%$ \\
\hline & $\begin{array}{c}\text { Temporal Allocation } \\
\text { Creating and interpreting temporal } \\
\text { structures to enable present and future } \\
\text { performance }\end{array}$ & $\begin{array}{l}\text { Temporal allocation, synchronization, } \\
\text { entrainment, coordination, pacing, routines, } \\
\text { scheduling }\end{array}$ & $\begin{array}{l}\text { "We identified three types of temporal institutional work in which actors } \\
\text { engaged in this context: constructing urgency, entraining, and enacting } \\
\text { momentum." (Granqvist \& Gustafson, 2016, p. 1019) }\end{array}$ & $9 \%$ \\
\hline \multirow[t]{2}{*}{$\begin{array}{l}\text { Associated action(s): Primarily } \\
\text { perceiving time built upon time } \\
\text { traveling. }\end{array}$} & $\begin{array}{l}\text { Time Awareness } \\
\text { Perceiving time itself, including its role } \\
\text { in present and future work and life }\end{array}$ & $\begin{array}{l}\text { Time awareness (increased or decreased), } \\
\text { concern for deadlines, economic value of } \\
\text { time }\end{array}$ & $\begin{array}{l}\text { "Time-urgent individuals tend to constantly check the status of time } \\
\text { remaining by attending carefully to the passage of time...[whereas] non- } \\
\text { time-urgent individuals tend to be less attentive regarding remaining time } \\
\text { resources and tend to under-estimate the passage of time." (Waller et al., } \\
\text { 2001, pp. 589-590) }\end{array}$ & $7 \%$ \\
\hline & $\begin{array}{c}\text { Temporal Construal } \\
\text { Mentally representing a future event } \\
\text { based on temporal distance (e.g., abstract } \\
\text { vs. concrete) }\end{array}$ & $\begin{array}{l}\text { Temporal construal (i.e., near term or } \\
\text { distant); perceived time frame; temporal } \\
\text { distance }\end{array}$ & $\begin{array}{l}\text { "Temporal construals refer to the way work group members interpret or } \\
\text { orient to time. Whether members...are more concerned with long-term plans } \\
\text { or immediate concerns are characteristic dimensions of the way time gets } \\
\text { construed by group members." (Ballard \& Seibold, 2003, pp. 385-386). }\end{array}$ & $6 \%$ \\
\hline \multirow{2}{*}{$\begin{array}{l}\text { COMPREHENDING } \\
\text { The means by which individuals } \\
\text { and collectives holistically } \\
\text { connect and understand past, } \\
\text { present and future }\end{array}$} & $\begin{array}{l}\text { Narrative } \\
\text { Sequencing of past, present, and future } \\
\text { experiences into a coherent story }\end{array}$ & $\begin{array}{l}\text { Narrative, antenarrative, storytelling, } \\
\text { rhetorical history, vectors, temporal } \\
\text { coherence, framing, trajectories, themes, } \\
\text { temporal bracketing }\end{array}$ & $\begin{array}{l}\text { "Narratives (stories) are meaningful sequences of events, and the } \\
\text { sequencing is essentially a function of time. Without time, there are no } \\
\text { temporal sequences, and hence no stories." (Baumeister et al., 2016, p. 8) }\end{array}$ & $30 \%$ \\
\hline & $\begin{array}{c}\text { Meaning } \\
\text { Understanding the significance of } \\
\text { experiences across the past, present, and } \\
\text { future }\end{array}$ & $\begin{array}{l}\text { Finding or making meaning, shared } \\
\text { awareness, construction/ } \\
\text { creation/destruction/ transference of } \\
\text { meaning }\end{array}$ & $\begin{array}{l}\text { "...managers used time not just as a simple linear measuring stick, but as a } \\
\text { shaper of social reality and meaning." (Staudenmeyer et al., 2002, p. 593) }\end{array}$ & $24 \%$ \\
\hline $\begin{array}{l}\text { Associated action(s): Primarily } \\
\text { interpreting time built upon } \\
\text { time traveling. }\end{array}$ & $\begin{array}{c}\text { Sensemaking } \\
\text { A social and/or individual process of } \\
\text { interpretation based on schemas built } \\
\text { over time }\end{array}$ & $\begin{array}{l}\text { Sensemaking, sensegiving, ideological } \\
\text { sensemaking, schemas, sensemaking as } \\
\text { identity construction, social- and self- } \\
\text { signaling }\end{array}$ & $\begin{array}{l}\text { "Sensemaking is a search for plausibility and coherence, that is reasonable } \\
\text { and memorable, which embodies past experience and expectations, and } \\
\text { maintains the self while resonating with others. It can be constructed } \\
\text { retrospectively yet used prospectively..." (Brown et al., 2008, p. 1038) }\end{array}$ & $23 \%$ \\
\hline
\end{tabular}

Note: Based on 133 articles (73 intersubjective; 60 intrasubjective). Some articles included more than one mechanism. 
TABLE 4

Types of Impact within Subjective Time Research

\begin{tabular}{|c|c|c|}
\hline Approach to Impact & Typical Characteristics & Exemplars \\
\hline \multicolumn{3}{|c|}{ Application to Existing Domains $\left(66 \%{ }^{a}\right)$} \\
\hline $\begin{array}{l}\text { Using subjective time concepts } \\
\text { and/or mechanisms to generate new } \\
\text { insights within an established } \\
\text { research domain }\end{array}$ & $\begin{array}{l}\text { Positioning subjective time concepts as key influences (e.g., } \\
\text { independent, moderating, or contextual variables) on pre- } \\
\text { existing relationships or outcomes }\end{array}$ & $\begin{array}{l}\text { The consideration of CEO temporal focus can predict a } \\
\text { firm's strategic decisions such as new product introductions } \\
\text { (Nadkarni \& Chen, 2014) }\end{array}$ \\
\hline \multicolumn{3}{|c|}{ Challenging Temporal Assumptions (45\%) } \\
\hline \multirow{4}{*}{$\begin{array}{l}\text { Using subjective time concepts } \\
\text { and/or mechanisms to challenge } \\
\text { implicit assumptions within a } \\
\text { research domain }\end{array}$} & Three assumptions frequently challenged: & \\
\hline & $\begin{array}{l}\text { 1. Phenomena presumed to be homogeneous are actually } \\
\text { heterogeneous }\end{array}$ & $\begin{array}{l}\text { Perceptions of time are not homogeneous at the team level, } \\
\text { they depend upon the heterogeneity of individual } \\
\text { perceptions within the team (Gibson et al., 2007) }\end{array}$ \\
\hline & $\begin{array}{l}\text { 2. Short-term and long-term perceptions (wehther past or } \\
\text { future) are presumed to be the same but they actually differ }\end{array}$ & $\begin{array}{l}\text { Memories are perceived differently by individuals } \\
\text { depending upon whether they are in the recent versus } \\
\text { distant past (Buehler \& Griffin, 1994) }\end{array}$ \\
\hline & 3. Phenomena presumed to be stable are actually dynamic & $\begin{array}{l}\text { Organizational identity is both enduring and fluid (Kreiner } \\
\text { et al., 2015) }\end{array}$ \\
\hline \multicolumn{3}{|c|}{ Improved Understanding of Subjective Time (20\%) } \\
\hline $\begin{array}{l}\text { Refining the definition, boundaries, } \\
\text { and processes associated with the } \\
\text { conceptualization of subjective time }\end{array}$ & $\begin{array}{l}\text { Identification or elaboration of subjective time } \\
\text { concepts and mechanisms by incorporating new } \\
\text { perspectives and/or influences from other domains. }\end{array}$ & $\begin{array}{l}\text { The new concept of "temporal shifts" (changes in the way } \\
\text { organizational actors experience time) explains the process } \\
\text { by which organizational change occurs (Staudenmayer et } \\
\text { al., 2002) }\end{array}$ \\
\hline
\end{tabular}

${ }^{\mathrm{a}}$ The combined percentages exceed $100 \%$ because some studies addressed more than one type of impact. 
TABLE 5

Three Roadmaps for Future Research on Subjective Time in Organizations

\begin{tabular}{|c|c|c|}
\hline $\begin{array}{c}\text { Introducing Subjective Time } \\
\text { to a Domain }\end{array}$ & $\begin{array}{c}\text { Expanding Comprehensive Usage } \\
\text { of Subjective Time }\end{array}$ & $\begin{array}{l}\text { Deepening the Understanding } \\
\text { of Subjective Time Itself }\end{array}$ \\
\hline $\begin{array}{l}\text { 1. Based on one's research interests, select one or } \\
\text { more subjective time actions (time traveling, } \\
\text { perceiving time, interpreting time) and levels } \\
\text { (intersubjective and intrasubjective) to study. }\end{array}$ & $\begin{array}{l}\text { 1. Take stock of how well one's research domain } \\
\text { has accomplished the three-step approach to the } \\
\text { left (e.g., subjective time reviews within a } \\
\text { specific domain). }\end{array}$ & $\begin{array}{l}\text { 1. Contemplate subjective time as a fundamental } \\
\text { search for meaning that underlies all other } \\
\text { subjective time concepts and mechanisms. }\end{array}$ \\
\hline $\begin{array}{l}\text { 2. Select applicable mechanisms (i.e., attending, } \\
\text { preparing, and/or comprehending) particularly } \\
\text { considering past, present, and future. }\end{array}$ & $\begin{array}{l}\text { 2. Leverage underdeveloped aspects of subjective } \\
\text { time, to incorporate new research questions with: } \\
\text { a) multiple levels and actions }\end{array}$ & $\begin{array}{l}\text { 2. Untangle the complexity of event time as both } \\
\text { subjective and objective. }\end{array}$ \\
\hline $\begin{array}{l}\text { 3. Select one or more types of impact (i.e., } \\
\text { application, questioning assumptions, and/or } \\
\text { developing subjective time itself). }\end{array}$ & $\begin{array}{l}\text { b) all three time frames } \\
\text { c) deeper types of impact }\end{array}$ & $\begin{array}{l}\text { 3. Unravel the paradox of objective time as both } \\
\text { interdependent with and dependent upon } \\
\text { subjective time. }\end{array}$ \\
\hline
\end{tabular}


FIGURE 1

The Nature of Subjective Time Relative to Objective Time

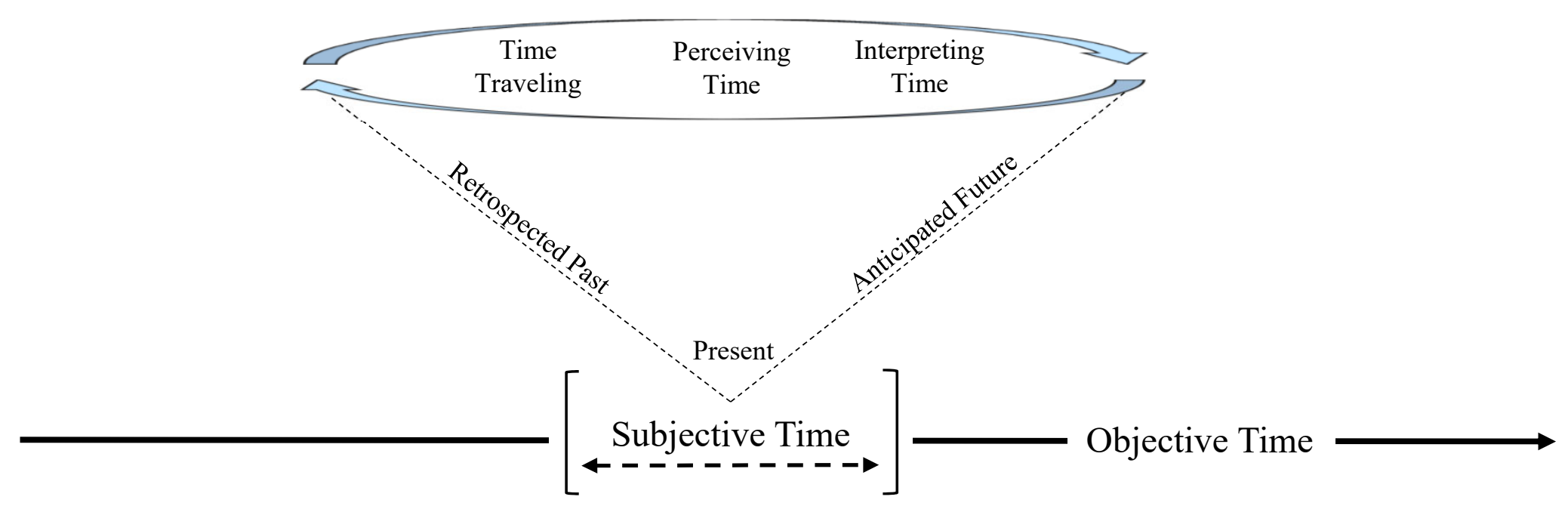

Note: The space denoted by the brackets acknowledges that subjective time (whether intersubjective or intrasubjective) can operate within as well as across objective time (i.e., in a mere instant or an extended period of objective time). Curved arrows between the past and future reflect recursiveness as individuals engage with subjective time. 


\section{APPENDIX \\ Glossary of Subjective Time Terms from Reviewed Articles}

A

Adjustment - Change in the individual to match the environment (e.g., role clarity, task mastery, and social integration; Ashforth, 2012*)

Affective forecasting - Current predictions of future emotional responses to events (Dane \& George, 2014*; see also Wilson \& Gilbert, 2003)

Anticipation - Perceiving future experiences based on current perceptions (Shipp \& Jansen, $2011 *)$

Anticipatory (in)justice - Expectations of how fair organizational practices will be (Cojuharenco et. al., 2011*; Jordan et al., 2019*; see also Shapiro \& Kirkman, 2001)

C

Chronos - Time as measured by the clock; "succession" (Jaques, 1982**)

Connected time - A temporal structure used to understand time (both objectively and subjectively) associated with being in communication with colleagues and the work environment (Reinsch et al., 2008*)

Consideration of future consequences - An individual difference that reflects the degree to which individuals consider distant versus immediate consequences of behaviors (Zhang et al., 2014*; see also Strathman et al., 1994)

Coordination - The collective accomplishment of goals through a cooperative process, typically involving communication (Ballard \& Seibold, 2003*)

Cultural dynamics - The evolution of cultures in terms of change versus stability (Hatch, 1993*)

Cultural perceptions of time - How people in various cultures experience concepts related to time (Brislin \& Kim, 2003*; Levine, 2005*)

Cycles (see also feedback cycles) - Repeated and rhythmic experiences over time, which can occur in clock time or event time (e.g., sales cycles, Dougherty et al., 2013*; see also Ancona \& Chong, 1996)

\section{D}

Distal goals - Long-term, ideal outcomes for the distant future, particularly those created by a leader (Shamir et al., 1994*)

Dynamics of citizenship behaviors - Patterns of extra-role behaviors over objective time based on evaluations from subjective time (Methot et al., 2017*)

Dynamics of strategic change - A processual approach to studying how strategy emerges, develops, and terminates (Kunisch et al., 2017*)

E

Entrainment - The adjustment of an activity's pace or cycle to synchronize with other cycles (Staudenmeyer et al., 2002*; see also Ancona \& Chong, 1996)

Event time pacing - Regulation of efforts based on events rather than the clock (Dougherty et al., 2013*; see also Gersick, 1994; Orlikowski \& Yates, 2002**)

Experiential vectors - The experience of temporality in strategic work that brings the future to the present or the past to the present (Vesa \& Franck, 2013*). 
$\mathbf{F}$

Feedback cycles - Receiving information about the outcomes of one's efforts as a process of communication to hold a person accountable for their efforts (Ballard \& Seibold, 2003*)

Fit narratives - Current stories that individuals craft using relevant retrospected, current, and anticipated fit perceptions (Shipp \& Jansen, 2011*)

Flow of time - A perception of time as passing from past to present to future (Hellström \& Hellström*; see also Doob, 1971**)

Foresight - Future thinking in which leaders make connections between the desired or invented future with the past and present (Cunha, 2004b*).

Future making - The process of enacting future realities based on present-day actions (Comi \& Whyte, 2018*)

Future oriented cognition (see also temporal focus) - Thoughts about the future due to context or individual differences (Strobel et al., 2013*)

Future selves - Future perceptions of oneself in terms of work aspirations (Costa \& Grey, 2014*; Strauss et al., 2012*; see also Markus \& Nurius, 1986)

\section{H}

Historical consciousness (see also organizational historicizing) - Appreciation of how past influences present understanding of future plans (Suddaby \& Foster, 2017*; see also Seixas, 2004)

Historical narrative - Telling and retelling of past and future stories to maintain continuity and make sense of organizational change (Maclean et al., 2014*; Ybema, 2014*).

\section{I}

(Organizational) Imagination - Future anticipations and aspirations relative to past and present circumstances (Carlsen, 2006*; Costas \& Grey, 2014*)

Interpreting change - Sensemaking processes that arise from interaction processes in response to organizational change over time (Balogun \& Johnson, 2005*; Bean \& Hamilton, 2006*)

K

Kairos - A "human" time of seasons, episodes, intentions, and flow (Jaques, 1982**)

\section{$\mathbf{L}$}

Legacy identification - The process by which organizational members presently maintain their self-definition from the past (Eury et al., 2018*)

Lingering identities - Work identities based on previous roles that last even after a role change (Wittman, 2019*)

Lived through experiences (see also temporality) - The experience of subjective time as shaped by history, context, and expectations (Dawson, 2014*)

Long present - Perceiving the present with an extended duration, which is inseparable from past and future (Kim et al., 2019*)

Long-term orientation - A preference to think about and value the future (typically by top management; Lin et al., 2019*; Reilly et al., 2016*; see also Lumpkin \& Brigham, 2011)

\section{$\mathbf{M}$}


Mental time travel - Recalling the past or anticipating the future (Dane, 2018*; see also Suddendorf \& Corballis, 2007)

Milestones - Events that serve as markers to evaluate progress (Dougherty et al., 2013*)

Mind wandering - A mental state characterized by thoughts disconnected from the situation at hand (Dane, 2018*; see also Smallwood \& Schooler, 2006)

Mindfulness - Attention and awareness of experiences in the present moment (Good et al., 2016*; see also Brown \& Ryan, 2003)

Momentum - The perceived force or energy associated with an activity, whether change-based momentum (moving to a new state) or stasis-based momentum (maintaining the status quo; Jansen, 2004*; Granqvist \& Gustafsson, 2016*).

$\mathbf{N}$

Nostalgia (see also postalgia) - A form of remembrance and longing for a romanticized past (Brown \& Humphreys, 2002*; Ybema, 2010*)

$\mathbf{O}$

Occupational future time perspective (see also temporal focus) - Perceptions of the future in terms of one's career (Rudolph et al., 2018*; see also Zacher \& Frese, 2009)

Organizational forgetting - intentional omission or neutralization of contradictory details in an organization's history (Anteby \& Molnar, 2012*; Feldman \& Feldman, 2006*)

Organizational history - Retrospective interpretation of an organization's past events (Suddaby \& Foster, 2017*)

Organizational historicizing - How actors use historical material to lend the authenticity of history to their actions (Hatch \& Schultz, 2017*)

Organizational identity endurance - Temporal continuity in an organization's defining characteristics (Anteby \& Molnar, 2012*; Kreiner et al., 2015*; see also Gioia et al., 2000)

Organizational memory - Information from the history of an organization that can be used for present decisions (Walsh \& Ungson, 1991*)

Organizational remembering - the culturally situated practice of using historical organizational experiences to collectively create meaning, often through stories (Adorisio, 2014*; Feldman \& Feldman, 2006*).

Organizational routines - Repetitive patterns or sequences of actions that are interdependent (Howard-Grenville, 2005*; see also Feldman \& Pentland, 2003)

Organizational time - An internal, social, multifaceted interpretation of time particular to an organization (Cunha, 2004a*; Gherardi \& Strati, 1998*)

(Organizational) time awareness - A cultural dimension within an organization for how much people plan and think about time use at work (Schriber \& Gutek, 1987*)

$\mathbf{P}$

Pacing style - Individual preference for allocation of time and efforts toward a deadline (e.g., early, steady, deadline; Mohammed \& Harrison, 2013*; see also Gevers et al., 2006)

Perceived time frames of teams - Anticipated ending of a team project as more or less distant (Bakker et al., 2013*)

Polychronicity - Individual preference for working on two or more tasks simultaneously deadline (Bluedorn \& Jaussi, 2008*; see also Bluedorn, 2002**) 
Postalgia (see also nostalgia) - projecting an optimistic future (Ybema 2010*; see also Ybema 2004).

Pragmatic prospection - Thinking about the future in a practical manner to guide present actions (Baumeister et al., 2013*)

Presentism - Attending to present concerns, whether as a lens through which to interpret the past or to the exclusion of future concerns (Berg Johansen \& De Cock, 2018*)

Prevailing temporal agenda - An individual's perception of organizational temporal structure (e.g., schedules, rhythms, and routines) that impact how the individual interprets, plans, and uses time at work (Blount \& Janicik, 2001*).

Psychological present - The immediate moment as represented by a short time frame (Bakker et al., 2013*; see also Lewin, 1943**)

\section{$\mathbf{R}$}

Reconstituting - Retrospectively reconstructing cultural artifacts to define culture (Hatch, 1993*)

Reconstructing - Reinterpretation of past events or projected future events to inform present actions (Comi \& Whyte, 2018*; Suddaby \& Foster, 2017*)

Recrafting - Recreating narratives based on perceived or actual changes across the past, present, and future (Shipp \& Jansen, 2011*)

Recreating - Reinterpreting past events to justify one's role in it (Kimberly \& Bouchikhi, 1995*)

Retrospection - Perceiving past experiences based on current perceptions (Shipp \& Jansen, 2011*)

Revising - Reinterpreting stories about one's identity over time (Ibarra \& Barbalescu, 2010*)

Rhetorical history - The process by which people interpret an organization's past for strategic purposes (Anteby \& Molnar, 2012*; Suddaby \& Foster, 2017*; see also Suddaby et al., 2010)

Right moment - Opportunistic moments in time, such as for decisions or actions (i.e., Kairos; Rämö, 2004*; see also Jaques, 1982**)

Risk horizon - Short versus long-term view of future decisions in terms of uncertainty and hazard (Das \& Teng, 1993*)

$\mathbf{S}$

Scenario planning - The strategic practice of creating contingent plans for the future through sensemaking, organizing, and storytelling (Bowman, 2016*; see also Schoemaker, 1993).

$\mathbf{T}$

Team temporal leadership - Team leader behaviors related to time (i.e., scheduling, synchronizing, and allocating resources) to address perceived issues of ambiguity, conflict, and scarcity of time (Mohammed \& Nadkarni, 2011*; see also McGrath \& Rotchford, $\left.1983^{* *}\right)$.

Temporal bracketing - Labeling of certain time intervals and episodes in terms of meaning (Jansen \& Shipp, 2019*; see also George \& Jones, 2000**; Langley, 1999)

Temporal depth (see also time horizon) - The temporal distance that individuals typically consider when thinking about past or future events (Bluedorn \& Jaussi, 2008*; see also Bluedorn, 2002**)

Temporal distance - Time between events or time frames (e.g., past and present, or present and future; Kunisch et al., 2017*) 
Temporal framing - Characterizing the past or future in a particular manner, such as the manner or speed with which the future approaches the present (Crilly, 2017*; see also Nadkarni et al., 2019)

Temporal focus (see also time perspective) - The degree to which individuals characteristically devote their attention the past, present, and/or future (Shipp et al., 2009*; see also Zimbardo \& Boyd, 1999)

Temporal individual differences - Time-based characteristics of individuals (e.g., temporal focus, time urgency, polychroncity, pacing style; Mohammed \& Harrison, 2013*)

Temporal institutional work - The process by which actors create and use norms about time (e.g., time frames and pace) to shape and change institutions (Granqvist \& Gustafsson, 2016*)

Temporal mental models - Shared understanding and mental representation of team members' views of time (Mohammed et al., 2015*; see also Standifer \& Bluedorn, 2006)

Temporal referent points - Anchor points for future perceptions that inform decision-making (Lin et al., 2019*)

Temporal responsiveness - The ability of individuals to adapt the timing of organizational activities in response to unanticipated events (Blount \& Janicik, 2001*)

Temporal shifts - Changes in the way organizational actors experience time (Staudenmeyer et al., 2002*)

Temporal settlements - Provisional strategic accounts that combine understanding of the past, present and future (Kaplan \& Orlikowski, 2013*)

Temporal spans - Ways of communicating that connect the past and/or future to the present to support organizational goals for consistency across moments (Forray \& Woodilla, 2002*)

Temporal structure - A rhythm of work that denotes a beginning and ending to a period of time, which can be used for collective coordination (Mohammed \& Nadkarni, 2011*; Staudenmeyer et al., 2002*; see also Orlikowski \& Yates, 2002**)

Temporal team cognition - Ideas about time within a team that are either overlapping and convergent (shared temporal cognitions) or complementary and divergent (temporal transactive memory systems; Mohammed \& Nadkarni, 2014*).

Temporal work - Addressing tensions (implicitly or explicitly) among different understandings of the past, present, and future to settle on a strategic account for the organization (Kaplan \& Orlikowski, 2013*)

Temporal zones (see also temporal depth and time horizon) - A focus on the short-term or longterm past or future (Nadkarni et al., 2016*)

Temporality (see also lived through experiences) - The ongoing relationships between past, present, and future (Schultz \& Hernes, 2013*; Dawson, 2014*)

Tensed versus tenseless time - Tensed time refers to a sense of flow with connections between past, present, and future, whereas tenseless time only refers to isolated "now" moments (Dawson, 2014*).

Time-bending sensemaking - Mental time travel to the past and the future to create a larger window in which to view one's identity in the present (Dahm et al., 2019*)

Time frames - Bracketed window of time around the past, present, or future or around an event (e.g., Bakker et al, 2013*; Kunisch et al., 2017*; McGivern et al., 2017*; Reilly et al., 2016*)

Time horizon (see also temporal depth) - A strategic focus on the future that varies in length from short-term to long-term, often to account for risk (Das, 1987*; Reilly et al., 2015*) 
Time perspective (see also temporal focus) - An individual's views of the psychological future and psychological past in the current moment; also used to describe temporal focus-orientations to the past, present, and future (Kooij et al., 2018*; Saunders et al., 2004*; Waller et al., 2001*)

Time scarcity - Viewing time as a resource that limited, whether objectively or subjectively (Ballard \& Seibold, 2006*; DeVoe \& Pfeffer, 2011*; see also Karau \& Kelly, 1992)

Time urgency - An individual difference that reflects the degree to which a person believes time is scarce and therefore feels chronically hurried and hyperaware of time (Mohammed \& Harrison, 2013*; Waller et al., 2001*; see also Landy et al., 1991).

Time visions - Team members' different interpretations of time based on cultural and social factors (Saunders et al., 2004*)

Timing changes - The degree to which organizational experiences deviate from one's original expectations for schedules, routines, and plans (i.e., hastenings versus delays; Blount \& Janicik, 2001*)

Trajectory - The shape or growth curve of individual or collective experiences from past to present and/or present to future (e.g., Kunisch et al., 2017*; Mitchell \& James, 2001**; see also Hernes, 2017)

\section{$\mathbf{V}$}

Value of time - Attributing an economic value to one's available hours (DeVoe \& Pfeffer, 2007*)

Note: Only terms used by articles within our sample are listed in this glossary. Terms we created for the mechanism clusters are defined in Table 3. Articles from our seminal review are denoted by ** and articles in our sample are denoted by *. 